\title{
RECONSTRUCCIÓN EN SUPERFICIE DEL PATRIMONIO GEOLÓGICO INACCESIBLE DE LA CAROLINA: LOS FILONES DE PLOMO ARGENTÍFERO
}

\author{
Concepción Fernández-Leyva \\ Instituto Geológico y Minero de España. Granada \\ c.fernandez@igme.es \\ ORCID iD: https://orcid.org/0000-0003-0625-1807 \\ Camilo Federico Alaminos Martín \\ IES Julio Palacios, San Sebastián de los Reyes. Madrid \\ camilo.alaminos@educa.madrid.org \\ ORCID iD: https://orcid.org/0000-0003-3278-3495
}

Recibido: 22/07/2020; Aceptado: 21/07/2021; Publicado: 03/12/2021

Cómo citar este artículo/citation: Fernández-Leyva, Concepción y Alaminos Martín, Camilo Federico (2021). Reconstrucción en superficie del patrimonio geológico inaccesible de la Carolina: los filones de plomo argentífero. Estudios Geográficos, 82 (291), e074. https://doi.org/10.3989/estgeogr.202185.085

RESUMEN: En el distrito minero de La Carolina se ha documentado una intensa actividad extractiva que se remonta a 4000 años de antigüedad. Pese a este extenso periodo de tiempo, la mayor parte del patrimonio que se conserva actualmente corresponde a los siglos XIX y XX, periodo en el que la minería del plomo argentífero experimentó un gran desarrollo. Chimeneas, tolvas, lavaderos, casas de máquinas y edificaciones auxiliares forman parte de este singular paisaje como testigos de la floreciente actividad económica que supuso la minería en esta zona. Sin embargo, los recursos naturales que propiciaron este desarrollo económico y social en La Carolina, y que determinan la configuración del paisaje tal y como hoy lo conocemos, pasa totalmente inadvertido por encontrarse oculto bajo la superficie. El presente artículo analiza, precisamente, aquellos elementos del patrimonio minero visible, directamente ligados a los filones, que nos permiten aflorar, en el marco del resto de bienes patrimoniales, ese patrimonio geológico oculto, contribuyendo a dimensionar el espacio minero de forma más fidedigna, al tomar en consideración todos los elementos patrimoniales geológicos y mineros, tanto visibles como ocultos.

PALABRAS CLAVE: patrimonio geológico; patrimonio minero; La Carolina; filones de plomo; pozo; escombrera

\section{SURFACE RECONSTRUCTION OF THE INACCESSIBLE GEOLOGICAL HERITAGE OF LA CAROLINA: THE ARGENTIFEROUS LEAD VEINS}

ABSTRACT: The intensive extraction activity dating back 4,000 years has been documented in the La Carolina mining district. Despite this long period, most of the heritage that is currently preserved corresponds to the 19th and 20th centuries, a period in which the mining of argentiferous lead experienced great development. Chimneys, hoppers, washing sites, machine houses and auxiliary buildings are part of this unique landscape as witnesses to the thriving economic activity that mining in this area brought. However, the natural resources that fostered this economic and social development in La Carolina, and that determine the configuration of the landscape, as we know it today go completely unnoticed because they are hidden below the surface. This paper analyses those elements of the visible mining heritage, directly linked to the underground veins, which allow us to emerge, that hidden geological heritage, in the heritage framework of this area. This help us to measure the mining space in a more reliable way by taking into account all the geological and mining inherited assets, both visible and hidden. KEY WORDS: geological heritage; mining heritage; La Carolina; lead vein; mining well; dum 


\section{INTRODUCCIÓN}

En los entornos mineros abandonados el legado patrimonial combina esencialmente aspectos geológicos con aspectos mineros; no se puede olvidar que la ubicación de las explotaciones no son fruto del azar, sino que es la geología la que determina, en primer lugar, la ubicación de los yacimientos, y la favorabilidad de ciertos factores como la riqueza, los costes de explotación y la existencia de vías comunicación efectivas, la que finalmente dicta la puesta en marcha de las explotaciones mineras. Tanto la extracción como el tratamiento posterior al que se somete el mineral, confieren al paisaje un legado que transciende al patrimonio geológico y minero; nos referimos al patrimonio histórico, arqueológico e industrial que, sumado a los ya citados, escriben la historia económica, tecnológica y social de un entorno. Por ello, proteger y preservar estos lugares contribuye a la transmisión y divulgación de la historia de los moradores de estos espacios y sus formas de vida (Pérez de Perceval y Sánchez, 2010). Organismos, como el Instituto Geológico y Minero de España, y sociedades, como la Sociedad Española para la Defensa del Patrimonio Geológico y Minero, desempeñan una labor fundamental en la promoción, difusión y coordinación de actividades encaminadas al estudio y protección del patrimonio geológico y minero-metalúrgico. A ellos se suman otras sociedades y administraciones locales, provinciales y autonómicas, interesadas en la rehabilitación turística y cultural del patrimonio minero en el marco del desarrollo sostenible. El antiguo distrito minero de Linares-La Carolina concentra gran parte del patrimonio vinculado a la minería metálica del Alto Guadalquivir, relacionado a su vez con la extracción del plomo argentífero acaecido en la zona (Arboledas et al., 2014). Dado que la explotación de los ricos filones metalíferos se remonta a 4000 años de antigüedad, son numerosas las huellas, tanto de época antigua como medieval e industrial, que ha dejado sobre el terreno la extracción de los recursos y la transformación de los mismos para su aprovechamiento (Arboledas, 2007; Contreras y Dueñas, 2010; Domergue, 2000; Gutiérrez, 2010). Sin embargo, el boom que experimentó la minería desde mediados del siglo XIX (con la instalación de la primera máquina de vapor en el año 1844) hasta los años 20 del siglo XX, especialmente agresivas por la aplicación de métodos y técnicas destructivas más eficaces, propiciaron la desaparición parcial o total de los restos pertenecientes a épocas anteriores, aunque quedaron debidamente documentados por los técnicos responsables de las explotaciones en la zona (Arboledas et al., 2014). Algunos, como Tamain (1974), utilizaron la información arqueológica como herramienta en la prospección minera en la zona de estudio. Las construcciones industriales que hoy día se conservan, y que son objeto de nuestro estudio, incluyen las instalaciones que las compañías mineras modernas, que operaron en el municipio, desarrollaron para la extracción de los recursos del subsuelo. El conjunto patrimonial conservado está formado por todas aquellas construcciones en superficie que son fácilmente identificables en un recorrido por el espacio minero de La Carolina. Chimeneas, tolvas, lavaderos, casas de máquinas y edificaciones auxiliares salpican el paisaje testificando lo que supuso la frenética actividad extractiva del plomo entre mediados del siglo XIX y el siglo XX.

Sin embargo, existe un patrimonio geológico de gran importancia que a ojos del visitante permanecería invisible, si no fuera por el emplazamiento en superficie de determinadas construcciones y restos de la actividad minera íntimamente ligadas a él y que permiten delinear su trazado en profundidad; nos referimos a los filones mineralizados objeto de esta floreciente actividad económica, y que salvo por los pozos y las escombreras, pasarían totalmente inadvertidos.

Los ricos filones metalíferos, emplazados en el subsuelo, se explotaron mediante galerías y pozos que permitieron llegar hasta ellos a cientos de metros de la superficie. En el caso de la Carolina, la explotación minera se iniciaba con la excavación de pozos verticales, para luego llegar a los filones a través de galerías horizontales excavadas a distintos niveles. Una vez el material era sacado y tratado para recuperar el mineral, el sobrante era acopiado en las escombreras, dándose en ellas la posibilidad de obtener de forma directa tanto muestras de la mineralización como de la roca encajante (De La Torre et al., 2010).

En algunas explotaciones mineras abandonadas, en las que han sido proyectados diferentes parques mineros, es fácil acceder al patrimonio geológico y minero del subsuelo a través de la habilitación de las galerías y pozos con determinados equipamientos que mejoran su accesibilidad y facilitan el recorrido. Hablamos de trenes mineros y de variados sistemas de transporte vertical, como ascensores y escaleras mecánicas, diseñados para permitir a los visitantes adentrarse en el mundo subterráneo de la minería (Pérez de Perceval y Sánchez, 2010).

Entre los ejemplos más reseñables de Parques Mineros Españoles se encuentran el de Riotinto en Huelva, el Parque Minero de Almadén en Ciudad Real, el 
Parque Tecnológico Minero de Andorra-Sierra de Arcos en Teruel y el Parque Minero de la Unión en Murcia; según Cañizares (2011) estos espacios son los referentes del denominado turismo minero de España, puesto que son una muestra de la minería asociada a cada contexto geográfico y geológico, con un patrimonio merecedor de conservación y estudio.

Entre la oferta que brindan estos espacios, la visita a las antiguas explotaciones mineras en forma de grandes cortas o galerías subterráneas, supone uno de los atractivos más valorados por parte del público interesado en este tipo de turismo; conocer cómo es el terreno bajo la superficie, tanto desde el punto de vista litológico como estructural, y cómo se encuentra el mineral alojado en él, suscita una gran curiosidad por parte de los visitantes. En el Parque Minero de Riotinto uno de los mayores reclamos, además del recorrido por la propia cuenca minera en tren, es el acceso controlado a dos grandes huecos de espectaculares dimensiones: la corta Atalaya en el municipio de Riotinto con 1.200 m de diámetro y 345 de profundidad y la Peña del Hierro en el municipio de Nerva, con 330 m en su eje mayor y más de 150 m de profundidad; en el Parque Minero de Almadén la contribución más importante es la visita a una mina real mediante el descenso por una galería subterránea, donde la zona accesible al público se localiza a unos $50 \mathrm{~m}$ de profundidad y da paso a diversas labores mineras de los siglos XVI al XIX, y en cuyo recorrido se observan interesantes aspectos geológicos del subsuelo (Hernández, 2004); en el Parque Minero de La Unión lo más llamativo para el visitante es un recorrido por las galerías subterráneas de la Mina Agrupa Vicenta a $80 \mathrm{~m}$ de profundidad. En todos estos ejemplos el patrimonio del subsuelo queda visibilizado gracias a las visitas a las explotaciones a cielo abierto y a los itinerarios trazados por galerías subterráneas (Cañizares, 2011).

En el caso que nos ocupa, el espacio minero abandonado de la Carolina, hay planteada una propuesta de reutilización de antiguas instalaciones mineras con fines turísticos y culturales (Galdón, 2018). Tras el análisis de los factores necesarios en la planificación de un espacio minero musealizado (Martín y Puche, 2000), dicha propuesta, finalmente se materializaría bajo el paraguas de un parque geológico-minero, contando con una atracción estrella: la unión del pozo del Sinapismo y el socavón de la Paloma, para ofrecer a los visitantes un descenso en ascensor de $162 \mathrm{~m}$ por el pozo y un recorrido, a pie o en vagonetas, de $500 \mathrm{~m}$ por la galería (Galdón et al., 2016, 2017). Sin embar- go, este ambicioso proyecto aún no se ha puesto en marcha debido a las severas dificultades técnicas que presenta y a la fuerte inversión que requiere para su materialización.

Teniendo en cuenta el papel protagonista que los filones metalíferos jugaron en la historia minera de la Carolina, y ante la imposibilidad actual de poder acceder a los mismos por la falta de instalaciones habilitadas para tal fin, nace la necesidad de ofrecer a los visitantes interesados en el turismo minero y de naturaleza, los elementos necesarios que les permitan recrear en superficie este patrimonio geológico oculto e invisible. No cabe duda que la configuración actual del espacio minero de La Carolina está condicionada por la disposición de los filones en el subsuelo, y que dar a conocer este patrimonio geológico "invisible", a través de los elementos patrimoniales mineros en superficie, es una contribución obligatoria para el entendimiento del patrimonio minero en su conjunto.

\section{OBJetivos Y MÉTOdO}

El objetivo de este trabajo es la puesta en valor de los filones mineralizados como legado patrimonial esencial en la historia de la extracción del plomo argentífero en La Carolina. Debido a la propia naturaleza de este patrimonio geológico, oculto bajo la superficie, inaccesible y por tanto invisible, los filones mineralizados pasan inadvertidos en el conjunto de vestigios vinculados a la minería y por ello, están infravalorados en el conjunto de los restos asociados a la actividad extractiva de este metal.

Si en un principio, la situación de los filones condicionó el emplazamiento de las instalaciones mineras, en este trabajo realizaremos la labor inversa, es decir, plantearemos la identificación de este patrimonio geológico oculto a través de los recursos estructurales que perduran en este territorio-museo. Crearemos un recurso, dentro de la línea argumental y didáctica del futuro parque geológico-minero, que mejore el entendimiento del paisaje al que nos enfrentamos, especialmente la distribución y función de los restos mineros, y que nos permita dimensionarlo de forma más fidedigna, al contar con los elementos patrimoniales geológicos y mineros, tanto visibles como ocultos.

Los principales elementos identificables en superficie y que se encuentran íntimamente ligados con el yacimiento mineral son los pozos y el resto de instalaciones mineras vinculadas a ellos, como el llamado conjunto de extracción, formado por la casa de 
máquinas y la casa de caldera. La casa de máquinas se situaba alineada con el pozo, protegiendo la máquina o máquinas alojadas en su interior; junto a ella se ubicaba la casa de calderas, encargada de proporcionar la energía a la maquinaria, y caracterizada por la presencia de grandes calderas de agua que debía ser calentada mediante combustión de madera o carbón, produciendo vapor de agua que era expulsado a través de una chimenea (Eiffel Lab, 2020). Así mismo, tiene especial importancia, sobre todo de cara a identificar los materiales en los que se encajan los filones, las escombreras, normalmente también situadas en las inmediaciones de los pozos.

En este trabajo aportamos las claves necesarias para valorar, en su conjunto, el espacio minero de La Carolina, incluyendo aquel patrimonio geológico que, siendo el elemento generador de todo el legado minero en superficie, carece de protagonismo por la dificultad que ofrece su apreciación, derivada de su ubicación en el subsuelo. Todo ello contribuirá a la recuperación, mantenimiento y conservación de estos espacios con fines didácticos, educativos, recreativos y turísticos

Con este fin, se ha realizado el estudio de las principales explotaciones del conocido espacio minero de la Aquisgrana en la Carolina, cuyo eje vertebrador es el antiguo trazado del ferrocarril inacabado entre el Guindo y esta población. Desde este trazado se accede a las minas del Castillo, La Rosa, El Sinapismo y La Aquisgrana, todas ellas explotadas en su momento para la extracción de la galena argentífera oculta en sus entrañas, y por ello, poseedoras de un rico patrimonio minero-industrial. En este trabajo, las minas mencionadas son descritas y documentadas prestando especial atención a los restos en superficie que son la clave para la interpretación in situ del patrimonio geológico oculto, facilitándonos información sobre la dirección, alineación y contenido mineral de los filones que fueron explotados en el pasado.

Metodológicamente, se ha recurrido a la revisión bibliográfica de gran número de documentos procedentes de variadas fuentes de información, combinado con el trabajo de campo en la zona. Para la identificación de las explotaciones abandonadas se ha tomado como punto de partida la información contenida en la base de datos de Recursos Minerales del Instituto Geológico y Minero de España así como documentación centrada en la descripción de las explotaciones y su patrimonio (Carrera et al., 2006; Dueñas et al., 2000); la toma de muestras mineralizadas y de documentos gráficos in situ, tanto de las propias explotaciones como de sus construcciones asociadas, completan el trabajo de campo.

\section{Contexto geOgráfico, geOlogico e históRico deL ÁREA DE ESTUDIO}

El municipio de La Carolina, incluido en el distrito minero de Linares-La Carolina, está situado en el norte de la provincia de Jaén, en la parte oriental de Sierra Morena, donde se encuentran numerosos vestigios relacionados con la extracción del plomo en la comarca (Fig. 1). El espacio minero de La Carolina se localiza al norte de la población, en el conjunto de cerros formados por el Río del Renegadero y sus afluentes, con el Río de la Campana en su margen izquierda, en torno al cual se encuentra la zona recreativa de la Aquisgrana. Se trata de un espacio dotado de zonas de merendero con barbacoas, extensos aparcamientos y un área de juegos infantiles en cuyo entorno se localizan las minas más antiguas de la zona: La Aquisgrana, La Rosa, El Sinapismo y El Castillo. También aquí se localiza el Centro de Interpretación de la Minería gestionado por la Asociación Minero Cultural Carolinense (A.C.M.I.C.A.), en un antiguo edificio minero cedido por el Ayuntamiento de La Carolina.

El distrito minero de Linares-La Carolina, que incluye los municipios de Bailén, Baños de la Encina, Carboneros, Guarromán, La Carolina, Linares, Santa Elena y Vilches, se estructura en dos subdistritos claramente diferenciados: el de Linares, al sur, y el de La Carolina, al norte, como claramente se observa en el Mapa Metalogenético de Linares Hoja 70 (Fig. 2), escala 1:200.000 (IGME, 1973). Aunque el gran desarrollo económico experimentado por ambos subdistritos se basó en la obtención del plomo argentífero del subsuelo, las notables diferencias en la geología de ambas zonas, determinó los métodos de explotación utilizados, y por tanto, la efectividad en el aprovechamiento del mineral y los costes de producción (Roll, 2012). Mientras que, en la zona de Linares, por estar los filones encajados en granitos, la extracción del mineral fue más lenta y costosa, en La Carolina los gastos se redujeron notablemente por encontrarse las venas mineralizadas en un terreno más fácil de trabajar, como cuarcitas y pizarras. A ello se sumó las diferencias en las tecnologías aplicadas en ambos emplazamientos, más rudimentarias en Linares al iniciarse antes la explotación, y más modernas y rentables en La Carolina al ser explotadas más tarde, coincidiendo con el declive de Linares.

Geológicamente, La Carolina se enmarca en el sector suroriental de la Zona Centroibérica del Macizo 
FIGURA 1.

UBICACIÓN GEOGRÁFICA DE LA CALROLINA Y DEL ESPACIO MINERO OBJETO DE ESTUDIO

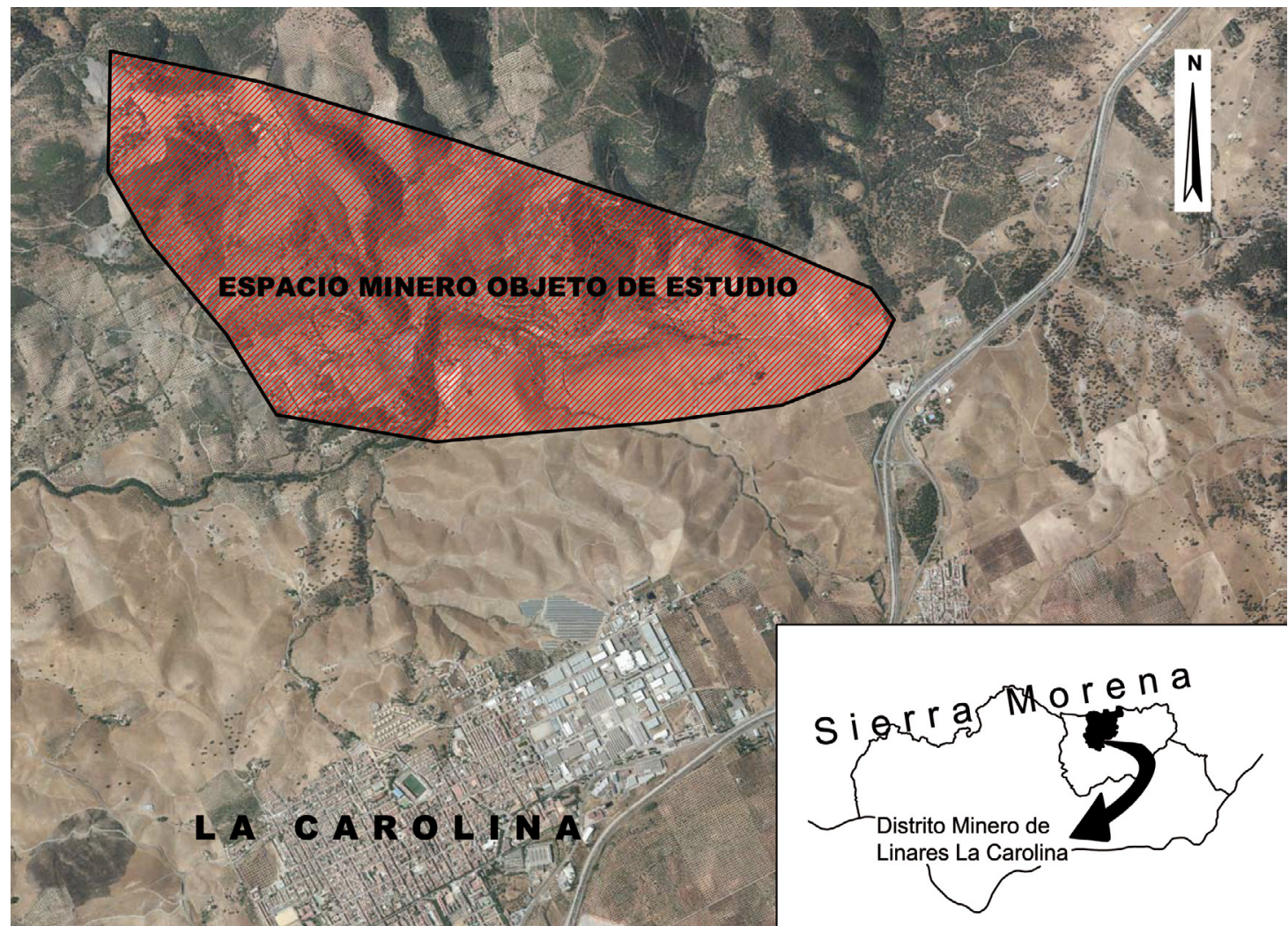

Fuente: elaboración propia

FIGURA 2.

ESQUEMA METALOGENÉTICO DEL DISTRITO LINARES-LA CAROLINA
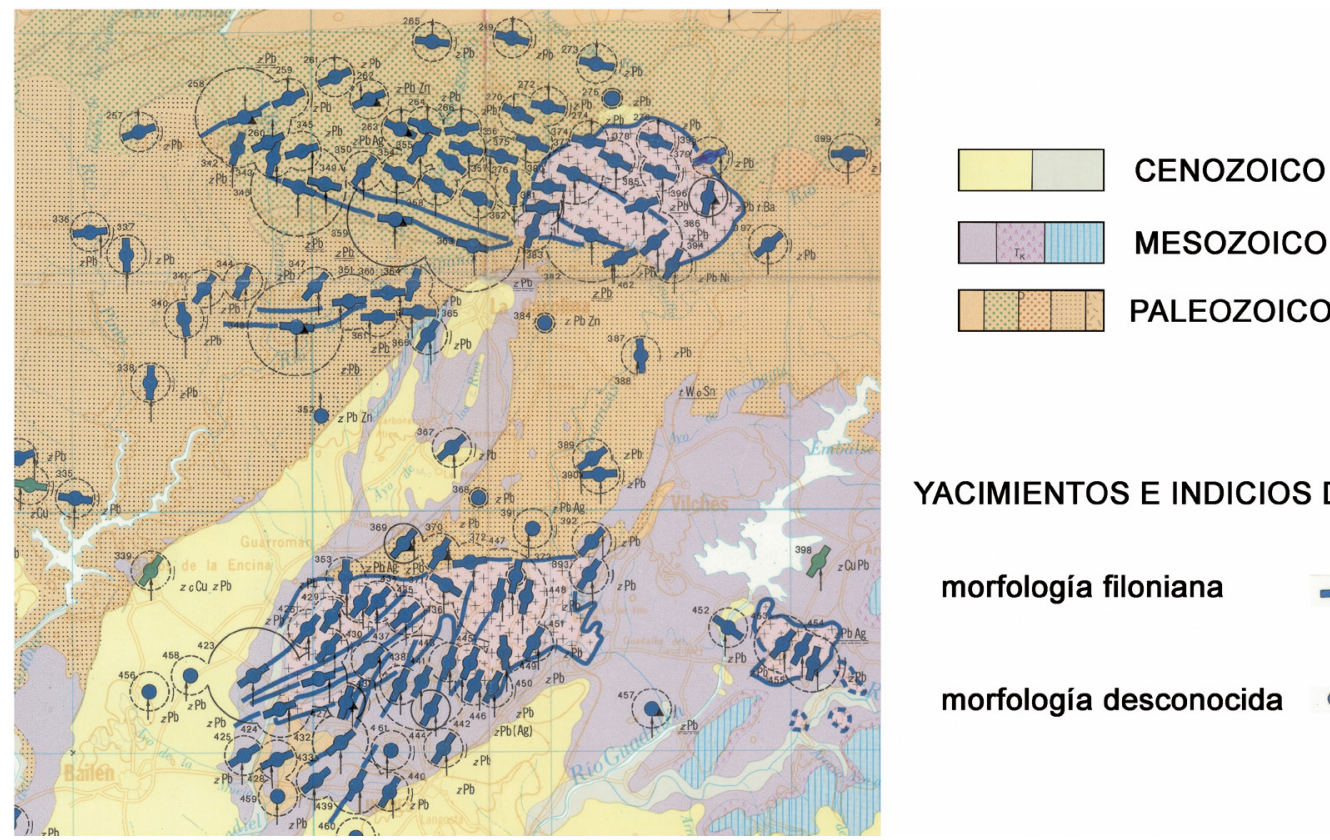

\section{YACIMIENTOS E INDICIOS DE Pb}

morfología filoniana

morfología desconocida

Fuente: Mapa Metalogenético de Linares Hoja 70 (Fig. 2), escala 1:200.000 
Ibérico. Afloran materiales paleozoicos afectados por un metamorfismo regional de grado medio a bajo, caracterizados por la sucesión de paquetes pizarrosos y cuarcitas armoricanas de edad Ordovícico a Carbonífero (Azcárate y Argüelles, 1971; Azcárate, 1977; Martín et al., 1982; Lillo, 1992; Rey e Hidalgo, 2004; Rey et al., 2005) (Fig. 3). Concretamente, las explotaciones se centran en las litologías de edad Ordovícico, especialmente en la Alternancia Superior también conocida como Serie de Galayo; conjunto constituido por la alternancia de cuarcitas y filitas, con espesores de 370 m (Dueñas et al. 2000).

La presencia de rocas plutónicas (granitos) emplazadas al final de la orogenia hercínica, que intruyen a los materiales paleozoicos (Martín et al., 2019), es una característica peculiar de este distrito. El origen del campo filoniano de La Carolina está asociado a las condiciones extensionales y al gradiente geotérmico anómalo originados al final de la orogenia hercínica. Las mineralizaciones se formaron tras un episodio extensional que produjo un magmatismo general facilitando la circulación de fluidos por los materiales encajantes.

Las densas redes de filones fueron explotadas para la extracción de la galena argentífera, de la que se obtenía plomo y plata (Castelló y Orviz, 1976). Valga como ejemplo de la estructura general de los filones bajo la superficie de la Carolina, el perfil de las labores realizado para el Grupo La Rosa-El Castillo (Fig. 4). El origen de este campo filoniano es equivalente al de Linares, y por tanto, asociado al tramo final de la orogenia hercínica, con las mismas condiciones extensionales y el mismo gradiente geotérmico anómalo. Según Tamain (1972) las mineralizaciones de este subdistrito son periplutónicas, del tipo B.P.G. (blenda, pirita y galena), generadas por la precipitación de flui-

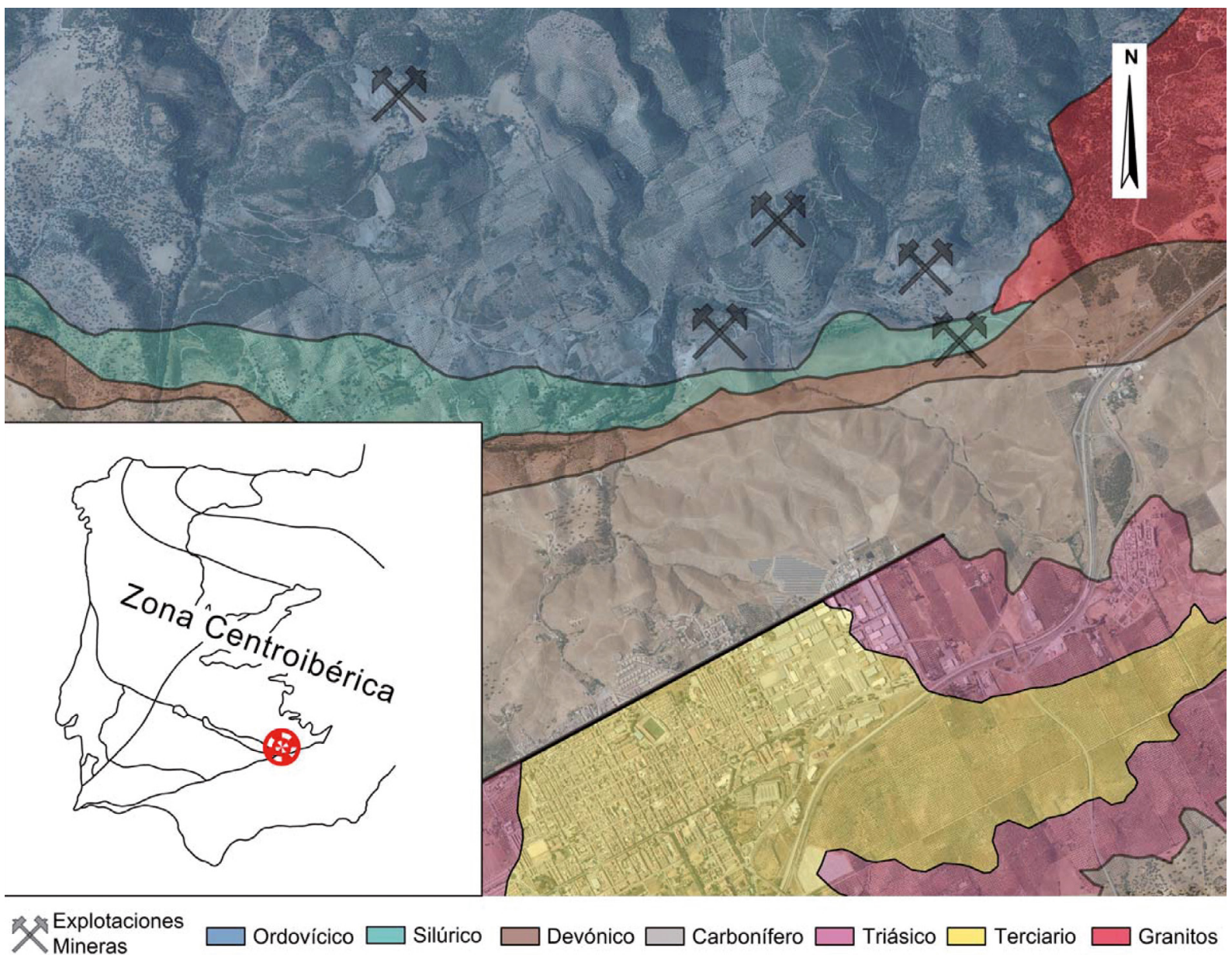

Fuente: Diseño de los autores a partir del Mapa Geológico no 884, escala 1:50.000 
FIGURA 4.

PLANO DE LABORES DE LOS FILONES EXPLOTADOS EN EL GRUPO LA ROSA-EL CASTILLO

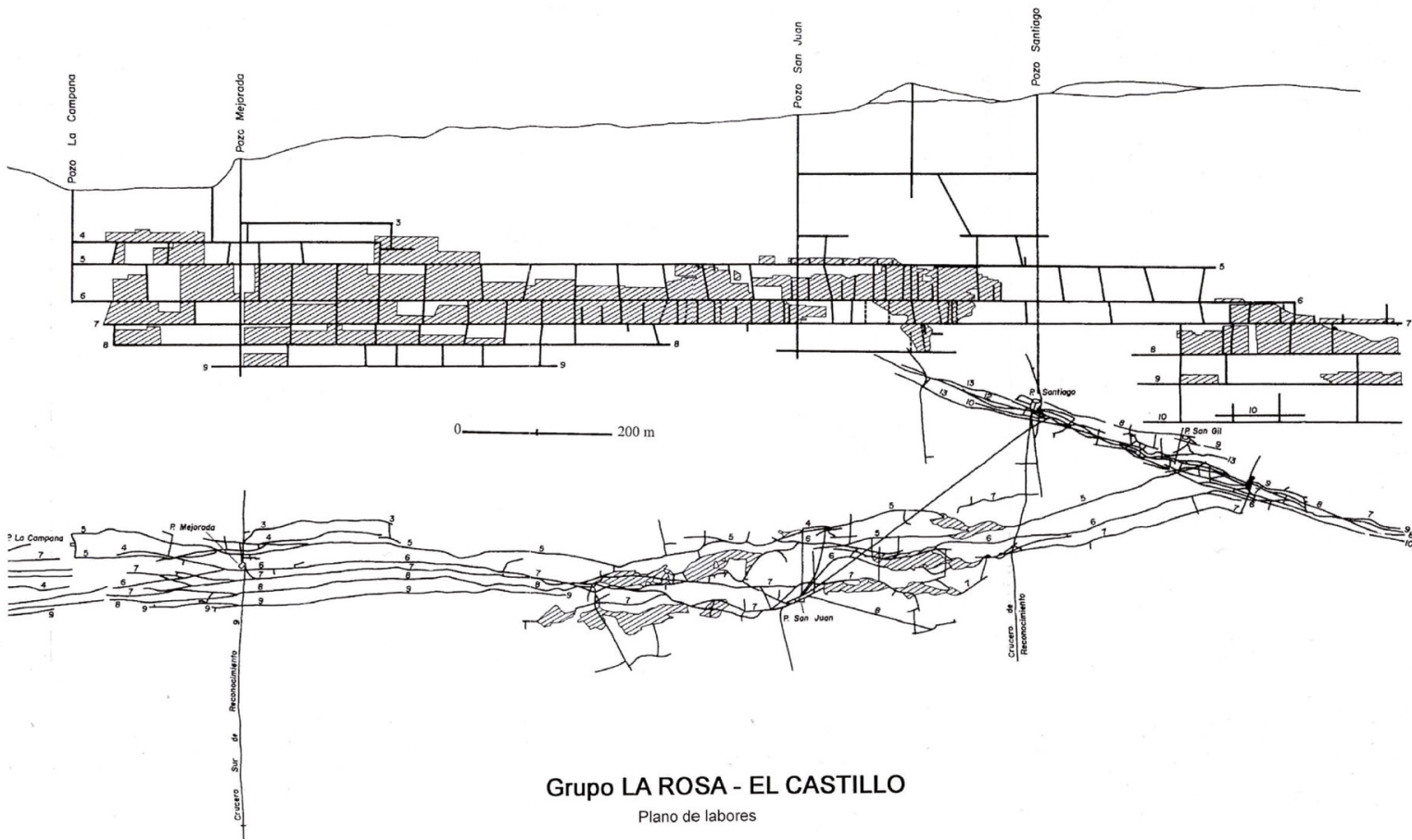

Fuente: Gutiérrez, F. (2007)

dos metalíferos que circularon por fallas y fracturas, cuya procedencia puede situarse en rocas ígneas no aflorantes. En la Cartografía de recursos minerales de Andalucía (García-Cortés, 2011), concretamente en la descripción de las mineralizaciones de la Zona Centroibérica (Boixereu et al., 2011) se puede encontrar un estudio más detallado sobre la metalogenia de la zona de estudio.

En la zona minera de La Carolina se pueden diferenciar varias familias de filones con desigual contenido mineral, según las direcciones medidas en los mismos (Azcárate, 1977): los filones N120E, los de mayor rentabilidad desde el punto de vista minero, seguidos de los filones de dirección N90E y N60E, con menor importancia, y los filones con dirección $\mathrm{N}-\mathrm{S}$, en general poco metalizados (salvo excepciones). Es claro que la litología, combinada con los factores mecánicos, juega un papel fundamental en la metalización en esta zona: los filones mineralizados más importantes encajan en cuarcitas, ya que al ser materiales más competentes admiten una fracturación franca y neta; los de menor importancia son los que arman en filitas, por ser materiales que reaccionan deformándose frente a esfuerzos mecánicos, viéndose así dificultada la creación de espacios abiertos donde alojarse el mineral (Dueñas et al.2000).
La historia del distrito minero Linares-La Carolina cuenta con cuatro milenios de antigüedad; en tan amplio periodo de actividad distinguimos una minería antigua, en la que los diferentes pobladores aprovecharon de forma desigual los recursos subyacentes de la zona, y de una moderna, considerada como tal y que se desarrolló desde 1841 hasta finales del XX. En este último periodo, la minería experimentó un espectacular desarrollo, favorecida por la incorporación de importantes avances tecnológicos (Gutiérrez, 2007) y una legislación ventajosa favorable a la inversión extranjera (Roll, 2012). La prosperidad económica que experimentó la zona a partir de la segunda mitad siglo XIX debido a la actividad minera (con más de la mitad de la producción nacional de plomo procedente de la provincia de Jaén), promovió una explosión poblacional como respuesta a la gran demanda de mano de obra (Colectivo Proyecto Arrayanes, 2010); mineros y trabajadores de toda España y Europa se desplazaron hasta la zona impulsando un fuerte crecimiento demográfico y la demanda de infraestructuras de comunicación y servicios que modernizaron la zona. A principios de los 70, se llevan a cabo una serie de informes, encargados por la Dirección General de Minas a la Empresa Nacional ADARO, para reactivar la minería nacional del plomo. El objetivo primordial era determinar el potencial metalífero residual del distrito, para lo cual, 
un equipo técnico, con el ingeniero Azcárate al frente de los trabajos, realizó un estudio geológico, estructural y metalogenético de los filones, obteniéndose resultados muy favorables (Azcárate, 1971; Azcárate y Argüelles, 1971). El resultado de toda esta actividad extractiva se materializaría en numerosos emplazamientos con restos de gran valor, tanto geológico como minero: minas, chimeneas, socavones, pozos, túneles, lavaderos, cabrias, escombreras y afloramientos geológicos singularizan el paisaje de La Carolina y revelan un pasado de floreciente actividad minera.

\section{ANÁLISIS DE LOS ELEMENTOS PATRIMONIALES EN EL ES- PACIO MINERO DE LA AQUISGRANA}

Las minas de la Carolina se localizan al norte de la población, en el conjunto de relieves situados junto al río Renegadero (de dirección NE-SO) y sus afluentes. El recorrido planteado por su zona minera, y que aprovecha el antiguo trazado ferroviario que conectaba $\mathrm{El}$ Guindo con la mina de La Rosa, y esta a su vez, con La Carolina y Linares, discurre por una superficie aproximada de $5 \mathrm{~km}^{2}$. Desde este trazado se puede acceder a las minas de El Castillo, La Rosa, El Sinapismo y La Aquisgrana (Fig. 5), entorno a las cuales se agrupan una serie de elementos patrimoniales de gran valor arquitectónico e industrial, relacionados todos ellos con la actividad extractiva del plomo. Se prestará especial atención a aquellas construcciones en superficie que permiten la delineación, reconstrucción y visualización en superficie del trazado y contenido de los filones en profundidad, dando cuenta de la dirección, dimensión aproximada y contenido mineral, así como el tipo de roca en que encaja la mineralización; se trata de las labores de acceso a los criaderos subterráneos, tanto pozos maestros como pozos auxiliares, y a los restos mineros que representan las escombreras.

\section{Mina La Rosa (1897-1907)}

Con anterioridad a la construcción de esta mina, también en La Carolina, hubo otra explotación con el mismo nombre en el cerro de Juan Bailén, registrada por José María Reinchart, y explotada entre 1870-1893. Esta primera Rosa se localizaba a $2.200 \mathrm{~m}$ al este de la explotación que poco tiempo después se pondría en marcha con el mismo nombre (Gutiérrez, 2007). Aunque muy prometedora por la producción alcanzada durante algunos años (55,2 t mensuales en 1880) (Martos, 1980), esta Rosa originaria fue abandonada en 1892, probablemente al no haber recibido la inversión necesaria para desarrollar una explotación más racional.

La mina La Rosa se localiza en una posición dominante, con vistas panorámicas hacia Sierra Morena, en el paraje Suerte Los Tramposos y Pechos del Sevillano, a unos 3 $\mathrm{km}$ al noreste de la ciudad. Esta explotación fue registrada el 2 de enero de 1897 por Mariano Robles Rodríguez, y formaba parte del grupo minero con el mismo nombre, junto con otras dos concesiones, San Francisco y San Juan (Gutiérrez, 2007). La rentabilidad que obtuvo Mariano Robles de La Rosa se desconoce, aunque se estima que serían de poca relevancia. En 1907 pasó a formar parte del grupo El Castillo-La Rosa (1907-1948) para beneficiar los filones de sus propios nombres.

El contexto geológico de esta explotación es la alternancia de tipo multilayer de pizarras, areniscas silíceas y cuarcíticas. El conjunto está metamorfizado por la

FIGURA 5.

VISTA PANORÁMICA DE LAS ZONAS EXPLOTADAS POR CADA UNA DE LAS MINAS

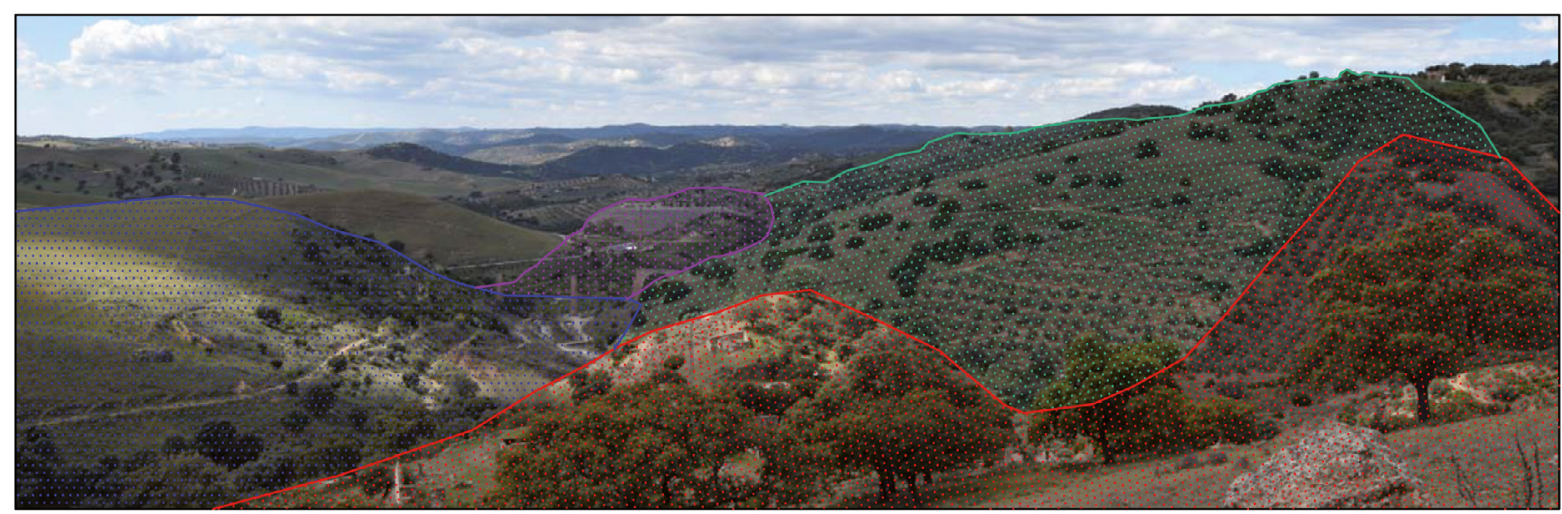

La Rosa EI Castillo El Sinapismo La Aquisgrana

Fuente: Diseño realizado por los autores 
FIGURA 6

TRAZADO EN SUPERFICIE DEL FILÓN DE LA ROSA

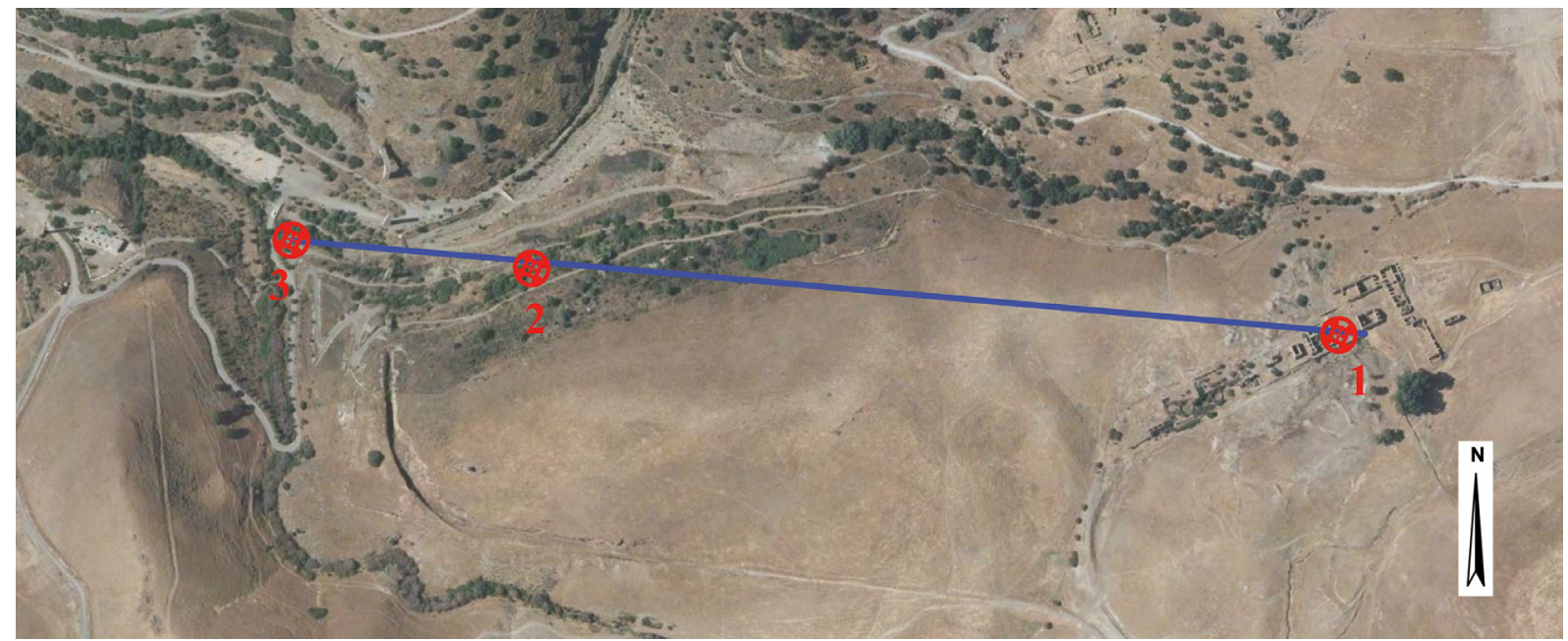

Fuente: elaboración propia a partir de los datos contenidos en la Tabla 1

cercanía al plutón de Santa Elena. Los filones mayoritariamente encajan en filitas y pizarras, coincidiendo la explotación con una zona de fractura en las alternancias litológicas mencionadas (Castelló y Orviz, 1976).

El objeto de la explotación es un importante filón de textura brechoide con una extensión lateral de más de 1.200 m, con una orientación N90E y buzamiento subvertical, con potencias generales que oscilan entre $1 \mathrm{y}$ 1,5 m (datos recogidos en la Base de Datos BDMIN ${ }^{1}$ del IGME). Según Gutierrez (2007) existen amplias zonas con un stockwork cuarzoso rico en galena, formado por una red de vetas al ramificarse el filón principal, que daba lugar a sectores de potencia hectométrica. Fuera de la zona de stockwork los filones encajaban en pizarras cámbricas. El filón de La Rosa fue muy rico especialmente en sus zonas centrales, mientras que hacia los extremos la metalización iba disminuyendo hasta desaparecer, como ocurría prácticamente con todos los del distrito de Linares-La Carolina (Galdón, 2018).

En cuanto a las labores mineras, hay tres pozos que nos permiten visualizar en superficie el filón, y que dan información aproximada sobre sus dimensiones y orientación: una longitud de al menos 978 m (distancia entre los pozos ubicados en los extremos del filón) y una dirección de N90E (Fig. 6). Sobre este filón hubo un pozo principal y dos pozos auxiliares. El

FIGURA 7.

POZO SAN JUAN E INSTALACIONES EN EL POBLADO MINERO DE LA ROSA

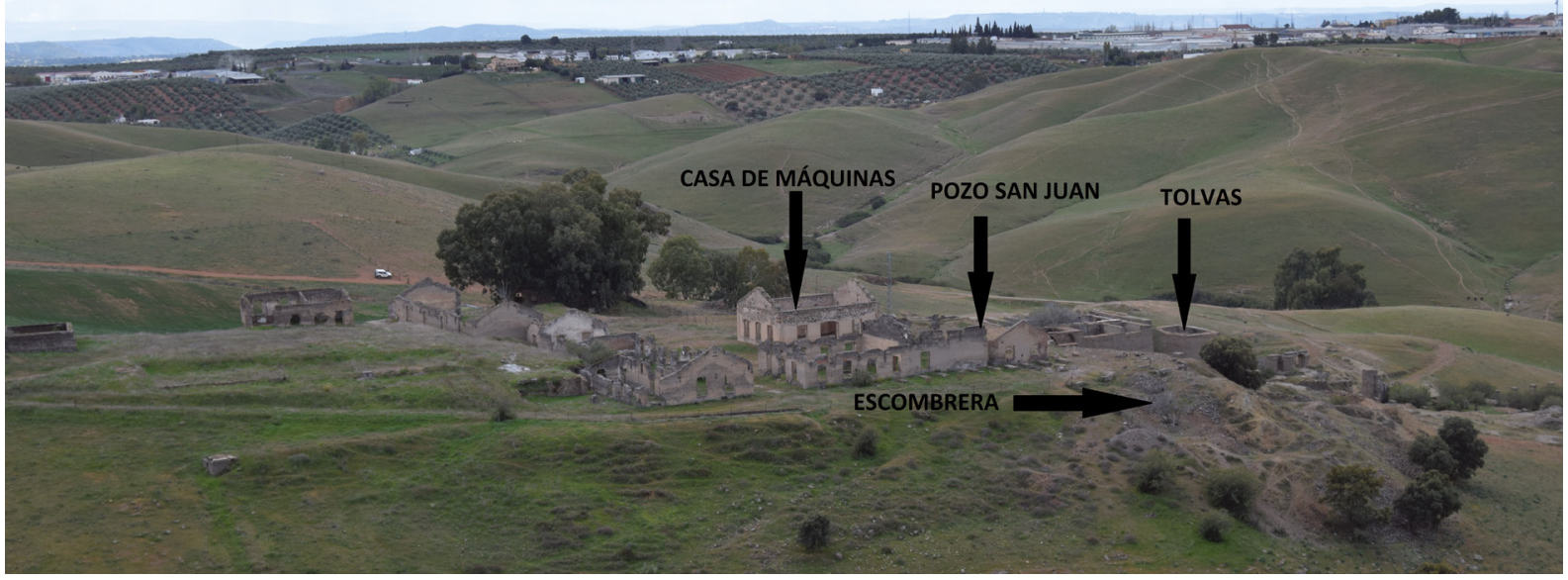

Fuente: Fotografía tomada por los autores 
FIGURA 8.

POZO MEJORADA DE LA MINA LA ROSA

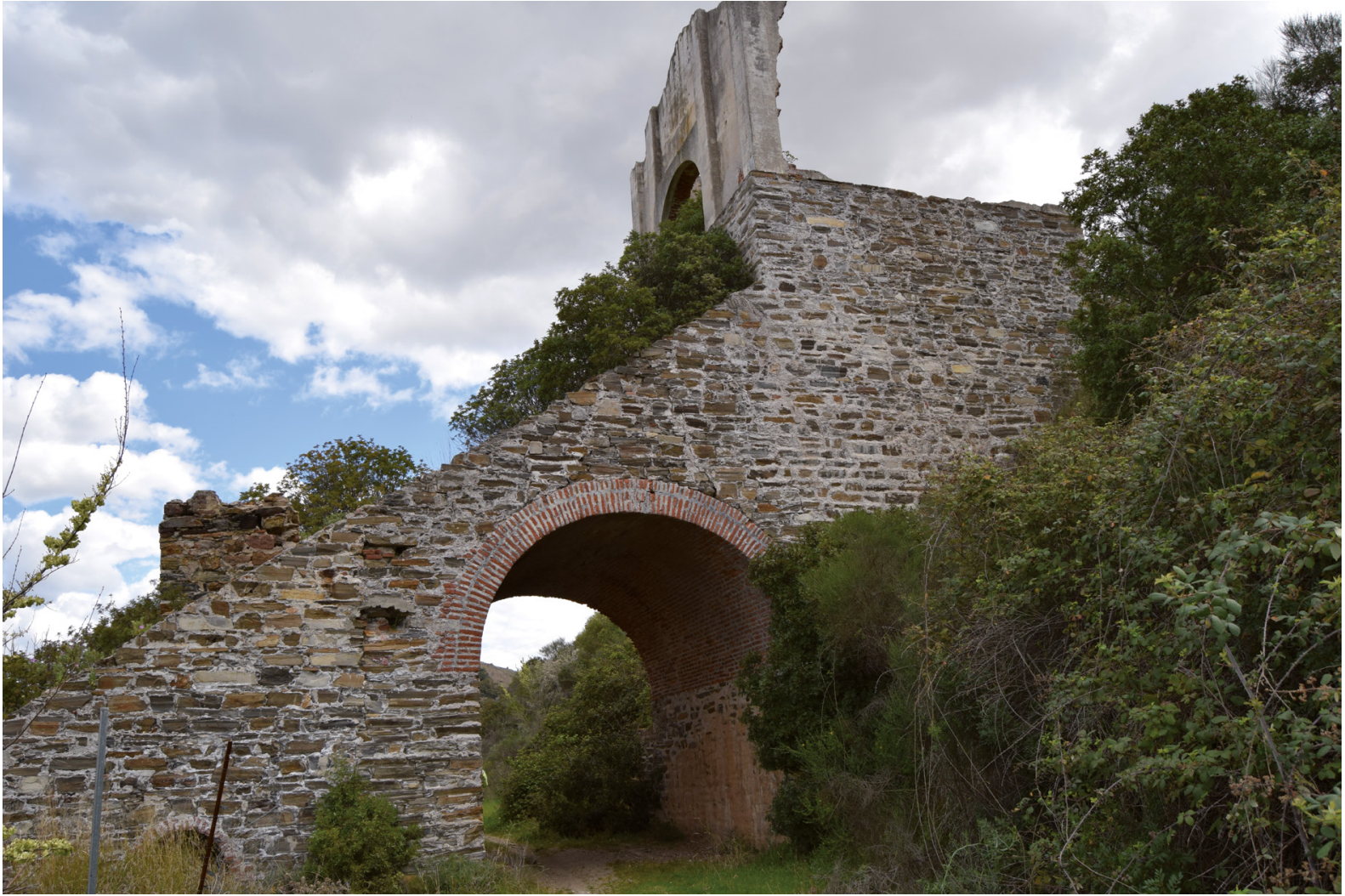

Fuente: Fotografía tomada por los autores

principal fue el pozo San Juan, situado en la parte de levante; alcanzó una profundidad de $330 \mathrm{~m}$ y estaba comunicado con los pozos Santiago y San Gil de la mina de El Castillo. Se considera la prolongación a levante del filón principal de la mina Aquisgrana. EI pozo San Juan se encuentra actualmente sellado, pero conserva espectaculares ruinas de las instalaciones mineras que han sido declaradas BIC por la junta de Andalucía, como así recoge el $\mathrm{BOJA}^{2}$ no 90; se trata de una casa de máquina de extracción, una casa de calderas, una casa de compresores, un lavadero, una tolva y un conjunto de edificios auxiliares (Fig. 7). A unos $800 \mathrm{~m}$ al oeste de San Juan está el pozo Mejorada, un imponente conjunto de mampostería sobre el que se asentaba la casa de la máquina de extracción y su castillete, con una gran arcada inferior para el paso del ferrocarril (Fig. 8); tenía una profundidad de 290 $m$ y contaba con un lavadero al que llegaba el mineral procedente de este pozo y del pozo San Ceferino, de la mina El Castillo. Unos 200 m más hacia el oeste está el pozo La Campana, cerca del río que le da nombre, junto al merendero del Parque Aquisgrana. En la Tabla 1 se recogen las coordenadas UTM de los pozos que
TABLA 1.

COORDENADAS UTM DE LOS POZOS QUE DEFINEN EL FILÓN DE LA ROSA (DATUM GEODÉSICO: ETRS89, USO 30)

\begin{tabular}{|c|l|c|c|}
\hline Corrida del filón & \multicolumn{1}{|c|}{$\begin{array}{c}\text { Nombre } \\
\text { del pozo }\end{array}$} & $\begin{array}{c}\text { Coordenadas } \\
\text { X_UTM }\end{array}$ & $\begin{array}{c}\text { Coordenadas } \\
\text { Y_UTM }\end{array}$ \\
\hline \multirow{3}{*}{ Filón La Rosa (571 m) } & 1. San Juan & 447734 & 4236862 \\
\cline { 2 - 4 } & 2. Mejorada & 446986 & 4238927 \\
\cline { 2 - 4 } & 3. La Campana & 446763 & 4238954 \\
\hline
\end{tabular}

Fuente: elaboración propia

definen el filón de La Rosa. También en el entorno, se pueden observar las escombreras, hoy día bastante desmanteladas, que nos dan información sobre los filones y sus rocas encajantes, y por tanto, debe considerarse como un patrimonio minero de interés geológico en el sentido de Díaz-Martínez (2017). Se calcula un volumen de escombrera de $3000 \mathrm{~m}^{3}$.

\section{Mina El Castillo (1825-1907)}

La mina del Castillo se localiza a $3 \mathrm{~km}$ al noreste de La Carolina y fue denominada así por estar situada en torno al castillo de Las Navas de Tolosa. El 5 de diciem- 
bre de 1825 se firmó el acuerdo para la explotación de los filones del Castillo. Se creó así una sociedad entre tres socios: el socio capitalista, Luis Figueroa y Casaus, y dos socios industriales, Pedro Pousivet y Juan de Bedat. Tras años de laboreo de los mismos, la explotación intensiva de los filones experimentó un gran avance a partir de 1843, alcanzando una producción de 1.530 t de minerales anuales en 1884, y manteniéndose en similares niveles hasta 1892 (Fernández, 1954). Hacia finales del siglo XIX (1893-96) la producción descendió bruscamente, para luego recuperarse hacia principios del siglo XX, promovido por un aumento en la cotización del plomo. En 1907 la Sociedad G. y A. Figueroa unificó la explotación de los filones El Castillo y La Rosa en un solo grupo, continuando así hasta 1948, cuando acontece el agotamiento y cierre definitivo de las minas situadas sobre ellos.

En 1913 la Sociedad Pañarroya se hizo con el grupo minero, desarrollando en los años siguientes una intensa explotación y modernización de las instalaciones de extracción y tratamiento del mineral (LópezMorell, 2003). Los cambios realizados mejoraron notablemente la producción, pasando de 1990 t a 11632 t en cuatro años, de 1925 a 1929; estos niveles de producción se mantuvieron hasta el año 36 , año en el que comienza la Guerra Civil y que marcará el declive de la producción hasta su cierre total en 1948 (Gutiérrez, 2007).

Geológicamente se encuentra en el mismo contexto que el de la mina La Rosa; una serie de cuarcitas y filitas metamorfizadas por la cercanía al plutón de
Santa Elena. Destaca la abundancia de pizarras mosqueadas, algunas con blastos aciculares de Andalucita y la presencia de fragmentos de granodioriotas milonitizadas.

El conjunto filoniano conocido como El Castillo es un importante filón de textura brechoide que se sigue en una corrida de aproximadamente $1,5 \mathrm{~km}$ y que se considera la prolongación a levante del filón del Sinapismo. Tiene una orientación general de N120E y un buzamiento de unos 80 a $85^{\circ}$ al sur (datos contenidos en la Base de Datos BDMIN ${ }^{1}$ del IGME). El desarrollo en profundidad fue de unos $350 \mathrm{~m}$, aunque en su parte más oriental llegó a los $500 \mathrm{~m}$, con una potencia media que llegaba a los $3 \mathrm{~m}$. Además del filón principal, hay otras estructuras paralelas en la parte meridional, que se siguen en unos $200 \mathrm{~m}$. Continuando las trazas hay un número considerable de pozos, los cuales permiten imaginar en superficie el complejo filoniano desarrollado en el subsuelo (Fig. 9). Así, sobre el filón septentrional se encuentra un pozo principal, Santiago, con una profundidad de $503 \mathrm{~m}$ y cuatro pozos auxiliares: San Gil (270 m), El Calvo (130 m), El Gavilán (95 m) y San Blas (50 m); la corrida de este filón, definida por la ubicación de los pozos en los extremos, es de $571 \mathrm{~m}$. La traza del filón central queda definida por un pozo principal, San Ceferino $(370 \mathrm{~m})$ y dos auxiliares: San Felipe (100 m) y Santo Tomás (360 m), al otro lado del río de La Campana; la corrida de este filón es de al menos $551 \mathrm{~m}$. Por último, el filón meridional, cuya corrida es de aproximadamente $493 \mathrm{~m}$, queda dibujado por el pozo San Eugenio $(160 \mathrm{~m})$ y un

FIGURA 9

TRAZADO EN SUPERFICIE DE LOS FILONES CORRESPONDIENTES A LA EXPLOTACIÓN DE EL CASTILLO

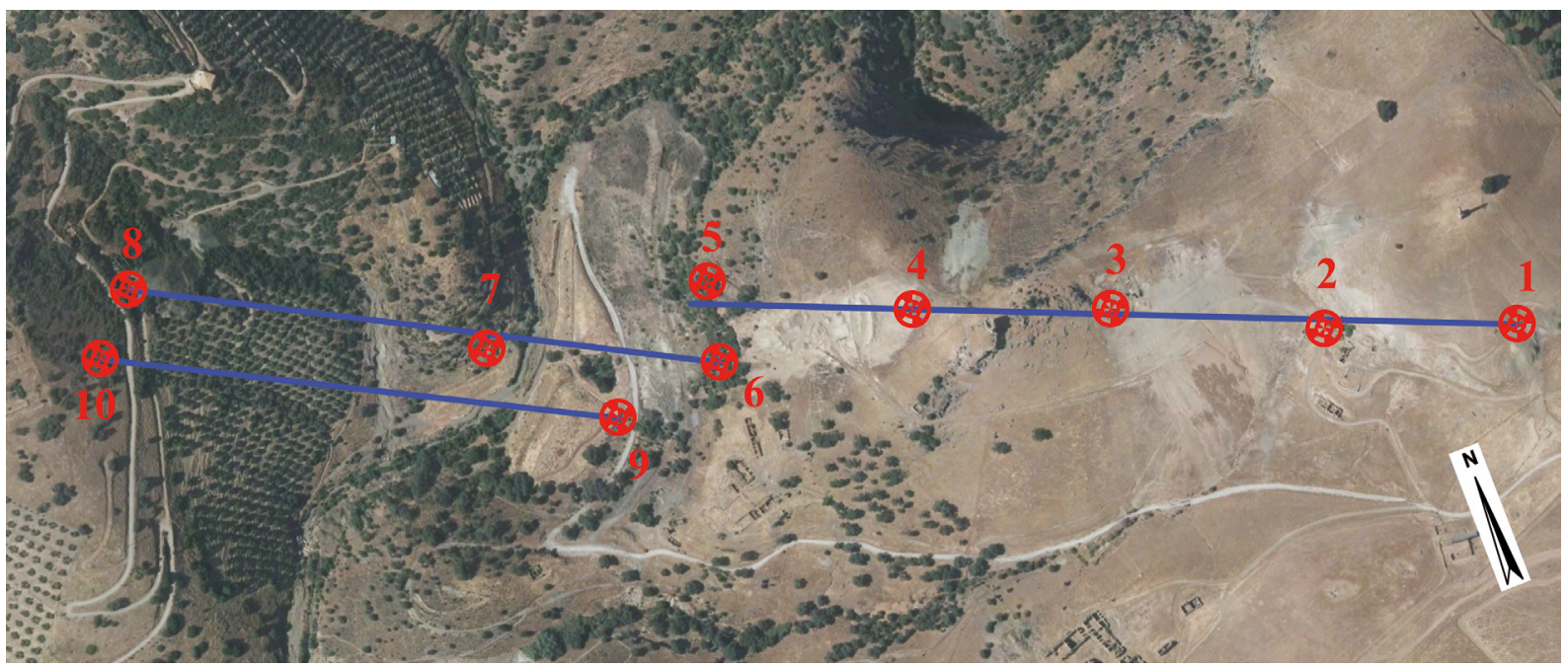

Fuente: elaboración propia a partir de los datos contenidos en la Tabla 2 
TABLA 2.

COORDENADAS UTM DE LOS POZOS QUE DEFINEN LOS FILONES SEPTENTRIONAL, CENTRAL Y MERIDIONAL DE LA MINA EL CASTILLO (DATUM GEODÉSICO: ETRS89, USO 30)

\begin{tabular}{|c|c|c|c|}
\hline $\begin{array}{c}\text { Corrida de los } \\
\text { filones }\end{array}$ & Nombre del pozo & $\begin{array}{c}\text { Coordenadas } \\
\text { X_UTM }\end{array}$ & $\begin{array}{c}\text { Coordenadas } \\
\text { Y_UTM }\end{array}$ \\
\hline \multirow{6}{*}{$\begin{array}{l}\text { Filón } \\
\text { Septentrional } \\
(571 \mathrm{~m})\end{array}$} & 1. San Juan & 447734 & 4236862 \\
\hline & 1. Santiago (Pozo maestro) & 448046 & 4239126 \\
\hline & 2. San Gil & 448242 & 4239077 \\
\hline & 3. El Calvo & 447879 & 4239198 \\
\hline & 4. El Gavilán & 447701 & 4239253 \\
\hline & 5. San Blas & 447539 & 4239311 \\
\hline \multirow{3}{*}{$\begin{array}{l}\text { Filón Central } \\
(551 \mathrm{~m})\end{array}$} & $\begin{array}{l}\text { 6. San Ceferino (Pozo } \\
\text { maestro) }\end{array}$ & 447503 & 4239257 \\
\hline & 7. San Felipe & 447308 & 4239332 \\
\hline & 8. Santo Tomás & 447002 & 439478 \\
\hline \multirow{2}{*}{$\begin{array}{l}\text { Filón } \\
\text { Meridional } \\
(493 \mathrm{~m})\end{array}$} & $\begin{array}{l}\text { 9. San Eugenio (Pozo } \\
\text { maestro) }\end{array}$ & 447414 & 4239242 \\
\hline & 10. Pozo auxiliar & 446959 & 4239423 \\
\hline
\end{tabular}

Fuente: elaboración propia pozo auxiliar excavado en roca. En la Tabla 2 se recogen las coordenadas UTM de los pozos que definen los filones septentrional, central y meridional de la explotación de El Castillo.

De esta mina sólo se conservan, en estado ruinoso, parte de una casa de bombeo Cornish, una casa de calderas, una chimenea y un lavadero, más una serie de edificios auxiliares del pozo Santo Tomás, como así recoge el BOJA² $\mathrm{n}$ 0 90. El brocal de este pozo está sellado por una losa de hormigón, frente a la cual se encuentra la escombrera, aunque ha sido en parte desmantelada. Se estima que quedan $40000 \mathrm{~m}^{3}$ repartidas entre las distintas labores, sobre todo en la parte de poniente. Cerca del pozo San Ceferino hay una balsa de estériles de unos $25000 \mathrm{~m}^{3}$. En la Figura 10 se observan las escombreras relacionadas con el pozo Santo Tomás y San Ceferino.

\section{Mina El Sinapismo (1873-1931)}

La mina del Sinapismo (donde se encuentra también el poblado minero con el mismo nombre) se localiza en torno al cerro de La Luna (a $708 \mathrm{~m}$ de cota), en la margen

FIGURA 10.

VISTA DE LOS POZOS SAN CEFERINO Y SANTO TOMÁS

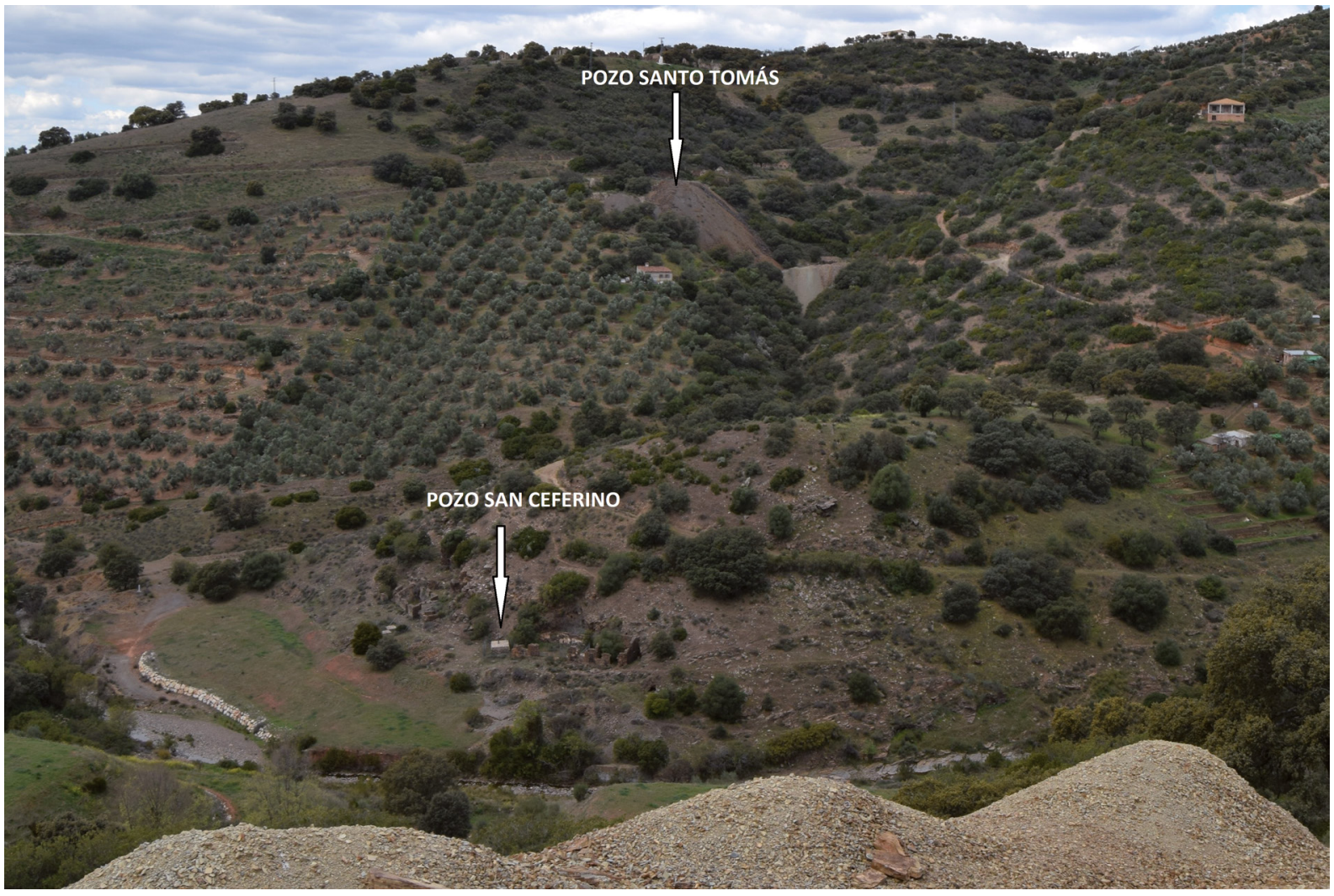

Fuente: Fotografía tomada por los autores 
FIGURA 11.

TRAZADO EN SUPERFICIE DE LOS FILONES CORRESPONDIENTES A LA EXPLOTACIÓN DE EL SINAPISMO

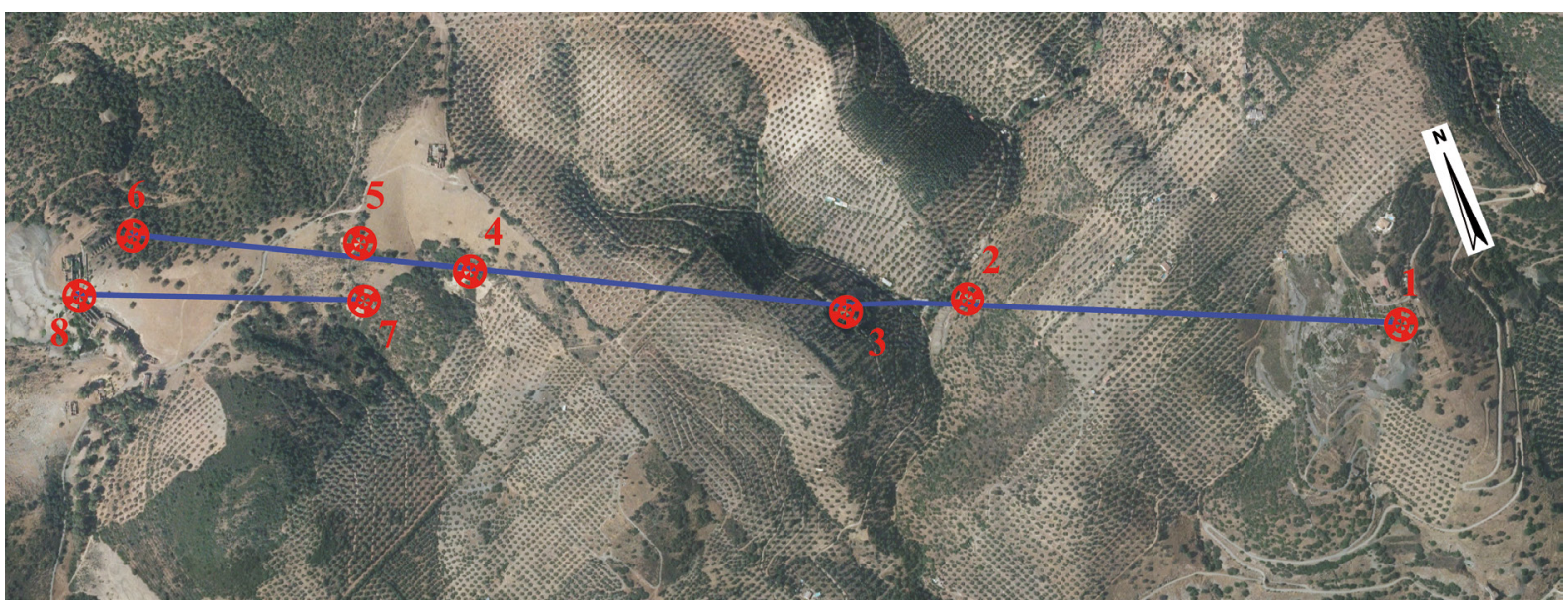

Fuente: elaboración propia a partir de los datos contenidos en la Tabla 3

derecha del río La Campana. Fue la primera mina demarcada (1873) de un gran grupo conocido como El Sinapismo-Coto Atila, propiedad de Hilarion Roux, empresario francés con intereses mineros y metalúrgicos en la Sierra de Cartagena (Pérez de Perceval Verde y López-Morell, 2008), aunque tiempo después pasó a manos de la Sociedad La Carolina. Durante unos años (1892-1905) las producciones fueron muy modestas o incluso nulas. A partir de 1905 la Sociedad Castilla La Vieja y Jaén se hace cargo de un grupo amplio de minas, incluida la mina El Sinapismo, bajo un contrato de arrendamiento obteniendo rentables beneficios en los años venideros: en 1907 y 1908 extrajeron una media de 4.600 t de mineral, 6.550 t en 1909 y casi 12.000 t en 1910 (Gutiérrez, 2007). En 1919, la Sociedad Castilla La Vieja y Jaén abandona el laboreo del filón, pasando a continuación a manos de diferentes arrendatarios en los años sucesivos, con fases de inactividad total. En el 1929, siendo propietario Isidoro Bodson, la producción de mineral era de $409,15 \mathrm{t}$. Las concesiones caducaron hacia finales de 1931 (Galdón, 2018). Años después la Compañía Minero-Metalúrgica Los Guindos adquirió las escombreras y el lavadero de El Sinapismo (Ministerio de Industria, 1971), para tratar, aproximadamente, $250 \mathrm{t}$ diarias de mineral. La actividad cesó definitivamente en 1982.

Geológicamente, la mina de El Sinapismo comparte escenario con las dos minas anteriores; los filones, encajados en el conjunto formado por la sucesión alternante de cuarcitas y filitas, se esterilizan en profundidad al penetrar en la Pizarra de Corredera (Dueñas et al., 2000).

Según Fernández (1954), se beneficiaron tres filones en 1909, si bien es cierto que los actuales restos patrimoniales que se conservan en superficie sólo proporcionan información de la existencia de dos (Fig. 11). El más importante, un filón de textura brechoide, que se extiende en unos $2 \mathrm{~km}$ de extensión, presenta un rumbo general $\mathrm{N} 120$ 으 y buzamiento fuerte hacia el sur. La potencia era de 1 a $3 \mathrm{~m}$, se explotó a lo largo de más de $6 \mathrm{~km}$ en distintos niveles y hasta una profundidad de $560 \mathrm{~m}$. Presentaba una metalización bastante continua en más de $1500 \mathrm{~m}$. Este filón es prolongación hacia el oeste del filón de El Castillo y se considera que continúa hacia el oeste por las minas Higueruela y Atila. Los pozos que nos permiten perfilar el filón en superficie son: un pozo principal, el del Sinapismo, y cinco auxiliares, dos de los cuales son pozos de ventilación. En función de estos pozos podemos establecer una corrida mínima del filón de $2.122 \mathrm{~m}$. Es interesante comentar que en torno al pozo principal se desarrolló el poblado del Sinapismo, cuyos restos han sido considerados BIC por la Junta de Andalucía, según recoge el BOJA ${ }^{2}$ no 90. Este poblado fue aumentando y continuamente modificando su estructura gracias a la construcción de nuevas viviendas, además de algunas instalaciones industriales entre las que se contó con un gran lavadero y algunas tolvas. Los restos que se conservan actualmente son muros, en estado ruinoso, cimentados mediante una amalgama de pizarras y ladrillo cerámico macizo con arcos peculiares y sin techumbre.

El trazado de un segundo filón a unos $100 \mathrm{~m}$ al sur del anterior, se puede interpretar gracias a la presencia de dos pozos: uno principal, el pozo Rafaelito, y otro auxiliar al este del principal. El filón presenta mineralización hasta una profundidad de $180 \mathrm{~m}$, y en 
una corrida de $400 \mathrm{~m}$, tal como se recoge en la Estadística Minera ${ }^{3}$ de 1909 , si bien la mineralización se empobrece definitivamente, tanto en dirección como en profundidad (Galdón, 2018). A partir de la separación entre los dos pozos se ha establecido una longitud mínima de $477 \mathrm{~m}$. En la Tabla 3 se muestran las coordenadas UTM de los pozos que definen los filones septentrional y meridional de la explotación de El Sinapismo.

TABLA 3.

COORDENADAS UTM DE LOS POZOS QUE DEFINEN LOS FILONES SEPTENTRIONAL Y MERIDIONAL DE LA MINA EL SINAPISMO (DATUM GEODÉSICO: ETRS89, USO 30)

\begin{tabular}{|c|c|c|c|}
\hline $\begin{array}{l}\text { Corrida de los } \\
\text { filones }\end{array}$ & Nombre del pozo & $\begin{array}{c}\text { Coordenadas } \\
\text { X_UTM }\end{array}$ & $\begin{array}{c}\text { Coordenadas } \\
\text { Y_UTM }\end{array}$ \\
\hline \multirow{6}{*}{$\begin{array}{l}\text { Filón } \\
\text { Septentrional } \\
(2122 \mathrm{~m})\end{array}$} & $\begin{array}{l}\text { 1. Sinapismo (Pozo } \\
\text { maestro) }\end{array}$ & 446829 & 4239500 \\
\hline & 2. Pozo ventilación & 446142 & 4239743 \\
\hline & 3. Pozo ventilación & 445948 & 4239788 \\
\hline & 4. Pozo auxiliar & 445380 & 4240032 \\
\hline & 5. Pozo auxiliar & 445192 & 4240118 \\
\hline & 6. Pozo auxiliar & 444845 & 4240245 \\
\hline \multirow{2}{*}{$\begin{array}{l}\text { Filón } \\
\text { Meridional } \\
(477 \mathrm{~m})\end{array}$} & 7. Pozo auxiliar & 445184 & 4240030 \\
\hline & $\begin{array}{l}\text { 8. Rafaelito (Pozo } \\
\text { Maestro) }\end{array}$ & 444729 & 4240173 \\
\hline
\end{tabular}

Fuente: elaboración propia
En esta explotación minera existía una galería, La Paloma, utilizada posteriormente como socavón de drenaje. Al conjunto de edificaciones hay que sumar un cable aéreo que transportaba, desde el pozo El Sinapismo, los materiales extraídos para ser tratados en el lavadero instalado en el pozo Rafaelito, y desde este, los minerales con destino a la fundición (Galdón, 2018).

El estudio de las escombreras, debido a su buena conservación, permite conocer la naturaleza geológica del subsuelo, tanto la mineralización como los materiales en los que encajan; la escombrera del pozo Rafaelito (Fig. 12) está casi intacta y contiene unos $230.000 \mathrm{~m}^{3}$ de materiales, mientras que la del pozo del Sinapismo está en gran parte desmantelada (restan en torno a $20.000 \mathrm{~m}^{3}$ ), aunque aún se puede reconocer en ella fácilmente fragmentos de la galena, que fue el objeto de explotación (Fig. 13).

\section{Grupo Aquisgrana (1880-1982)}

Las concesiones que forman este grupo se localizan junto al arroyo Los Tramposos, a $2 \mathrm{~km}$ al norte de La Carolina, por el camino hacia la antigua zona minera. El origen de este grupo, propiedad de la sociedad alemana Stolberg y Westfalia (Muñoz et al, 2002), fue la concesión registrada en 1880 con el nombre de La Aquisgrana (en honor de la ciudad alemana de Aquisgrán, dónde tenía su sede la compañía minera). Sobre ésta, más tarde, en 1886, se registraría La Aquisgra-

FIGURA 12.

ESCOMBRERA DEL POZO RAFAELITO EN LA EXPLOTACIÓN EL SINAPISMO

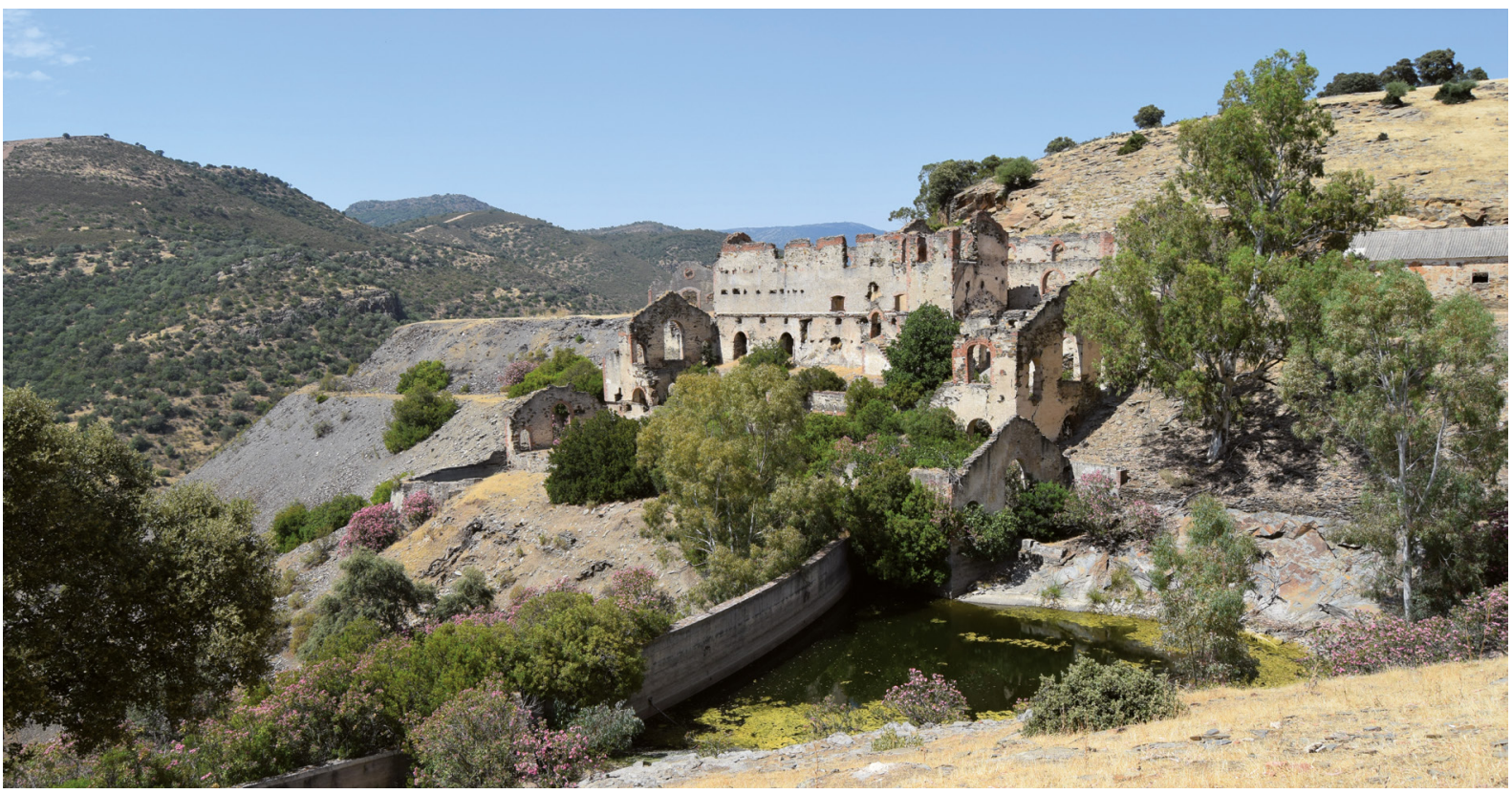

Fuente: Fotografía tomada por los autores 
FIGURA 13.

DETALLE DE LA GALENA ARGENTÍFERA PROCEDENTE DE LA ESCOMBRERA DEL SINAPISMO

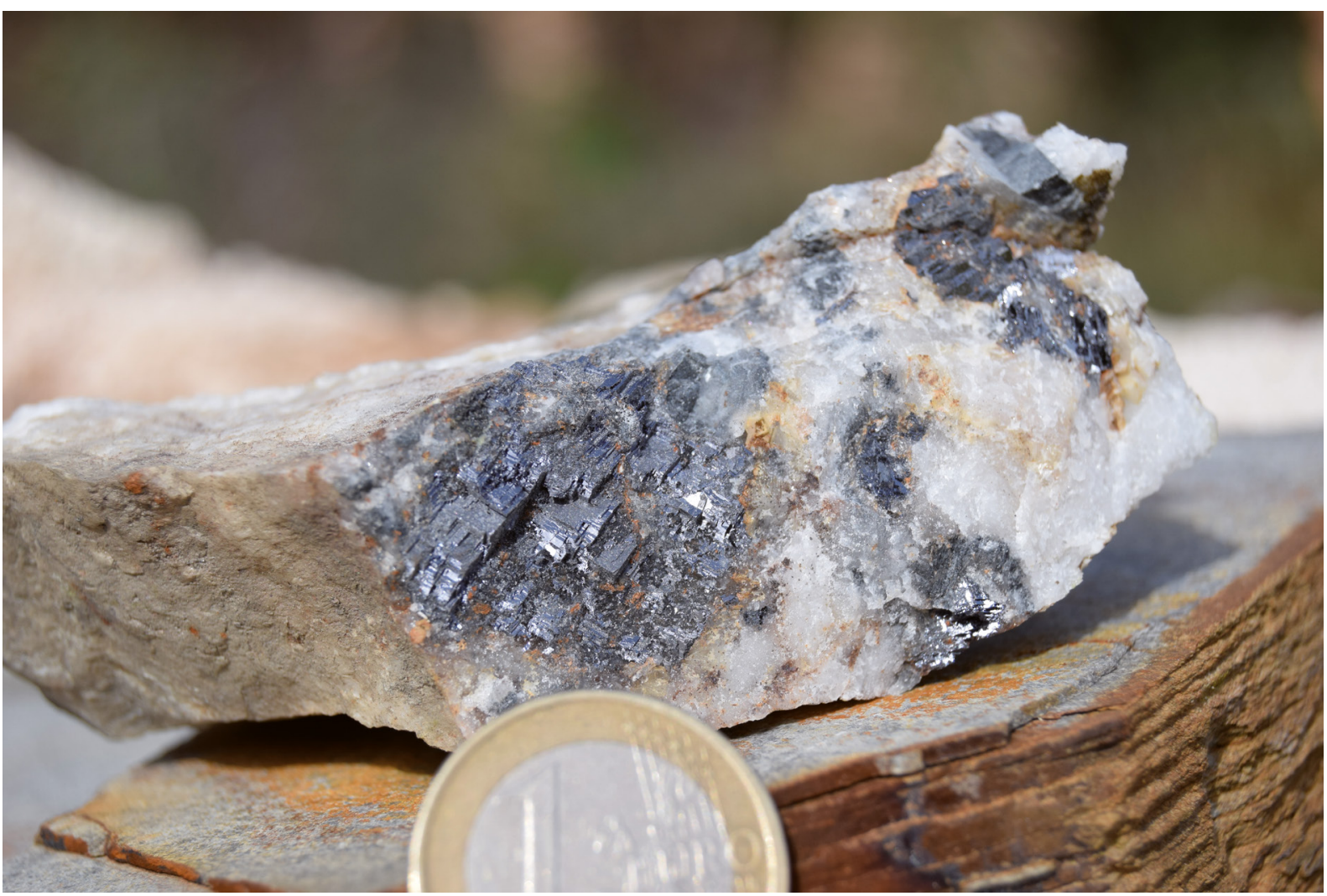

Fuente: Fotografía tomada por los autores

na II, por el potencial que tenía la zona al ser cruzada por la prolongación de los filones de La Rosa y el filón de Los Guindos, localizado este último al oeste de La Aquisgrana, fuera de nuestra zona de estudio. Años más tarde, se registró otra mina llamada La Aquisgrana III fue también registrada, que era colindante con la anterior y explotaba los filones mencionados. Continuarían, en los años venideros, el registro de una serie de "aquisgranas" con ordinales consecutivos, llegando hasta La Aquisgrana X, en 1907, e incluso con apelativos que resultaron en La Aquisgrana a Poniente y La Aquisgrana del Río, registradas en 1906 y 1907, respectivamente (Gutiérrez, 2007).

Durante la primera década del siglo XX se obtuvieron unas producciones medias anuales de concentrados de $1.500 \mathrm{t}$, aproximadamente; el avance total de exploración se eleva a 1.387 m lineales en el año 1911, seguidas en varias ramificaciones, según se recoge en la Estadística Minera ${ }^{4}$ de 1911. En 1920, el grupo pasó a ser propiedad de la Compañía Minero Metalúrgica Los Guindos, que mantuvo las labores sobre las antiguas demarcaciones, sin alcanzar nunca las cifras logradas por la sociedad alemana Stolberg y Westfalia.
El empobrecimiento de los filones a medida que se ganaba en profundidad propició la drástica caída de la producción en 1928, lo que provocó, finalmente, la paralización de la explotación en 1929. Del primitivo grupo apenas quedan restos: tan solo una gran chimenea, las ruinas de los pozos y algún socavón. El lavadero que Los Guindos instaló sobre La Aquisgrana en 1973 aún se mantiene en relativo buen estado.

Para la extracción de material el pozo principal fue el pozo Aquisgrana II, con una profundidad de 340 m; el pozo Aquisgrana III, con $405 \mathrm{~m}$, sólo fue utilizado para la extracción de materiales estériles.

Si bien, como hemos comentado, a lo largo de los años se llegó hasta registrar hasta La Aquisgrana $X$ (Gutiérrez, 2007), en nuestro estudio sólo consideramos las tres primeras, al ser las únicas que hoy día poseen restos patrimoniales identificables en superficie, imprescindibles para la recreación de los filones ocultos en el subsuelo.

En cuanto a la geología, esta zona se encuentra en el mismo contexto geológico: filones que encajan en las alternancias de filitas y cuarcitas ordovícicas. 
FIGURA 15.

CENTRO DE INTERPRETACIÓN DE LA MINERÍA GESTIONADA POR LA ASOCIACIÓN MINERO CULTURAL CAROLINENSE (A.C.M.I.C.A.)

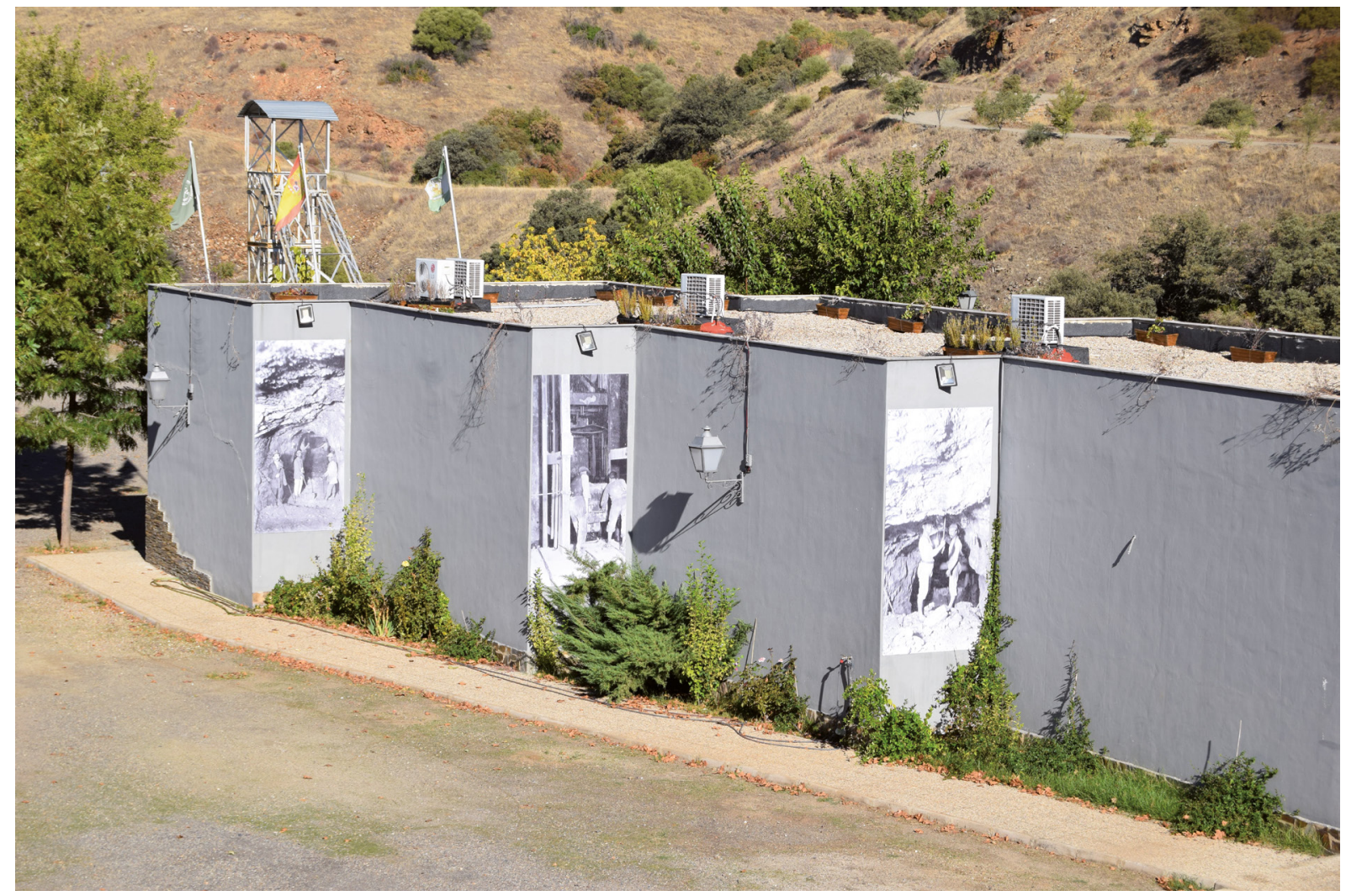

Fuente: Fotografía tomada por los autores

FIGURA 14.

TRAZADO EN SUPERFICIE DE LOS FILONES CORRESPONDIENTES A LA EXPLOTACIÓN DE LA AQUISGRANA

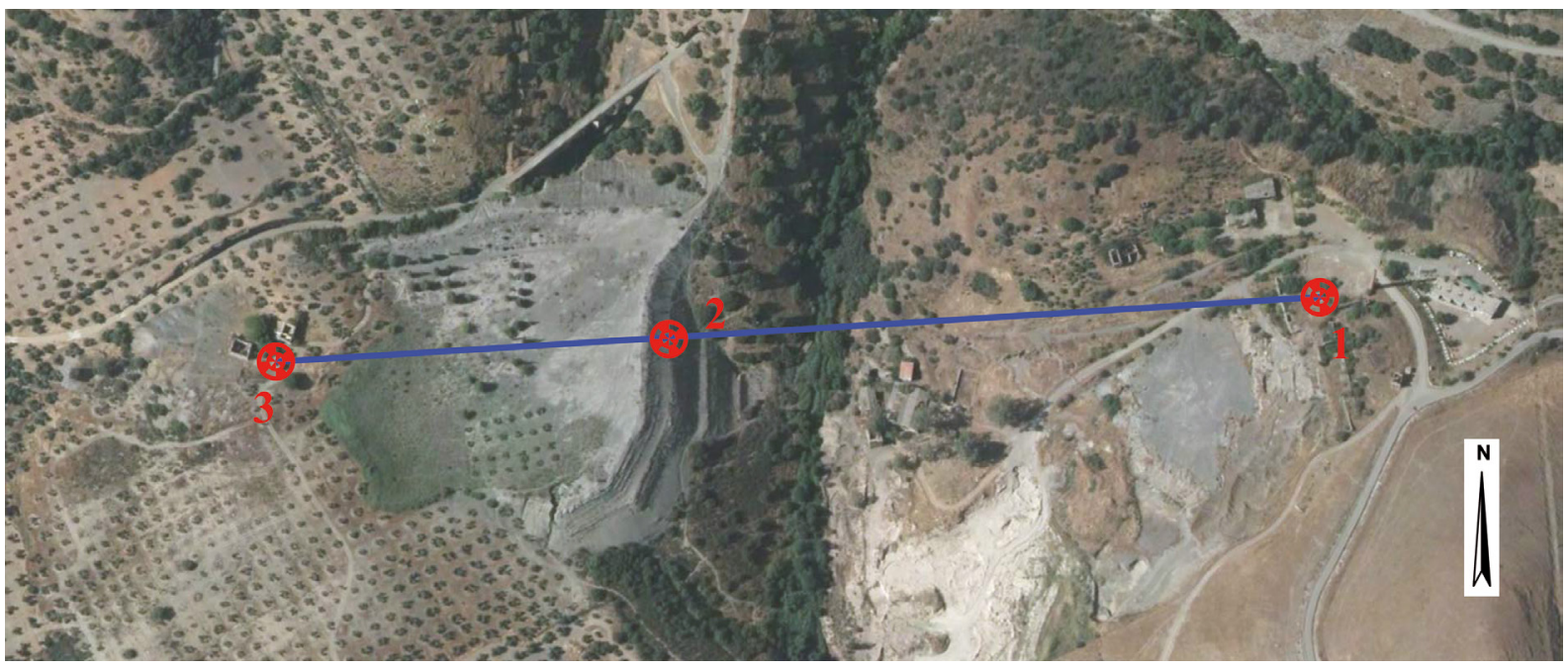

Fuente: elaboración propia a partir de los datos contenidos en la Tabla 4 
Aunque el Grupo Aquisgrana se encuentra en el cruce de dos filones, el de La Rosa y el de Los Guindos, este último situado en los relieves en la confluencia del río del Renegadero con el río Grande, el rendimiento de la explotación fue mucho menor de lo que fueron estos filones en sus sectores correspondientes, que eran muy ricos y productivos en sus zonas centrales, y más pobres hacia sus extremos que precisamente coincidían en la Aquisgrana. Los filones recibieron los nombres de Rama Pendiente y Principal. El primero lleva una dirección N110E y se considera el extremo suroriental del gran filón El Guindo; el segundo lleva una dirección aproximada N90E, siendo la misma que el filón de La Rosa. El campo de explotación en esta mina era de unos $800 \mathrm{~m}$ y los filones se trabajaron hasta profundidades del orden de $380 \mathrm{~m}$. Los buzamientos medios eran de 80 a 85 으 al sur.

Los restos que aún se conservan, únicamente permiten dibujar en superficie el trazado del filón principal; de este a oeste se puede seguir la corrida del mismo, de unos $597 \mathrm{~m}$, gracias a la disposición de dos pozos (Fig. 14), actualmente sellados con losas de hormigón y bovedilla. El pozo Aquisgrana I es el que se halla en la margen izquierda de río de la Campana y alcanzaba una profundidad de $340 \mathrm{~m}$; el pozo Aquisgrana III está a $580 \mathrm{~m}$ al oeste del primero, y se encuentra en la margen derecha del río, con una profundidad de $405 \mathrm{~m}$; entre ambos pozos había un tercero de $60 \mathrm{~m}$ de profundidad, tapado actualmente por la balsa de estériles, que sería el Aquisgrana II.

Las escombreras están desmanteladas en su mayor parte, quedando escasamente unos $19.000 \mathrm{~m}^{3}$; junto al pozo Aquisgrana III hay una gran balsa de estériles con unos $200.000 \mathrm{~m}^{3}$ de materiales finos.

En el entorno que ocupó esta histórica mina se ha construido recientemente una área recreativa y el Centro de Interpretación de la Minería gestionada por la Asociación Minero Cultural Carolinense (A.C.M.I.C.A.) como se observa en la Figura 15. En cuanto a restos patrimoniales se identifica una casa

TABLA 4.

COORDENADAS UTM DE LOS POZOS QUE DEFINEN EL FILÓN DE LA AQUISGRANA (DATUM GEODÉSICO: ETRS89, USO 30)

\begin{tabular}{|l|l|c|c|}
\hline $\begin{array}{c}\text { Corrida del } \\
\text { filón }\end{array}$ & \multicolumn{1}{|c|}{ Nombre del pozo } & $\begin{array}{c}\text { Coordenadas } \\
\text { X_UTM }\end{array}$ & $\begin{array}{c}\text { Coordenadas } \\
\text { Y_UTM }\end{array}$ \\
\hline \multirow{2}{*}{$\begin{array}{l}\text { Filón La } \\
\text { Aquisgrana } \\
\text { (597 m) }\end{array}$} & 1. Pozo Aquisgrana I & 446504 & 4238954 \\
\cline { 2 - 4 } & 2. Pozo Aquisgrana II & 446132 & 4238931 \\
\cline { 2 - 4 } & $\begin{array}{l}\text { 3. Pozo Aquisgrana III } \\
\text { (pozo maestro) }\end{array}$ & 445908 & 4238917 \\
\hline
\end{tabular}

Fuente: elaboración propia de calderas, una chimenea y varias bases de chimeneas antiguas, más una serie de construcciones auxiliares junto al pozo Aquisgrana I. También cuenta con un lavadero de mineral, formado por una nave metálica de cinco pórticos dobles, así como diversa maquinaria (cintas, machacadora, trituradora). En la Tabla 4 se muestran las coordenadas UTM de los pozos que definen el filón explotado en la mina de La Aquisgrana.

\section{CONCLUSIONES}

En los espacios mineros abandonados, como es el caso de La Carolina, las chimeneas, pozos y otras construcciones mineras e industriales definen un paisaje cuyo elemento generador, como en cualquier paisaje minero, radica en la geología que se encuentra en el subsuelo. La existencia de minerales de plomo ha dado lugar a un importante patrimonio cultural relacionado con su extracción y comercialización durante casi cuatro milenios de historia, si bien, su máximo esplendor, es alcanzado en la segunda mitad del siglo XIX y primer cuarto del XX.

La recuperación de este espacio para fines turísticos, didácticos e incluso deportivos pasa, no sólo por poner en valor todas aquellas instalaciones visibles y fácilmente identificables, en muchos casos sobradamente descritas y documentadas, sino también por asignar el papel protagonista a los elementos generadores del paisaje resultante, a los que estas construcciones superficiales, espacial y funcionalmente, están vinculadas: el patrimonio geológico.

En este trabajo se recoge una iniciativa, en el marco de la musealización del espacio minero de La Aquisgrana, encaminada a reconstruir el patrimonio geológico a partir de los restos en superficie de la actividad minera. Para ello, el patrimonio geológico y el patrimonio minero han sido estudiados y documentados, lo que ha permitido, entre otros aspectos, establecer la relación entre ambos. Este recurso, desarrollado dentro de la línea argumental y didáctica del futuro Parque Minero, mejorará el entendimiento del paisaje tal y como lo estamos viendo, porque, la propia organización del mismo, plantea un problema a esta tentativa: las instalaciones superficiales, que representan solo una parte del conjunto patrimonial vinculado a la actividad minera, están subordinadas a la mineralización subyacente, la cual permanece inaccesible y ampliamente desarrollada bajo la superficie. De esta forma, el patrimonio geológico pasa totalmente desapercibido ante la dificultad de ser contextualizados físicamente. 
En particular, serán los pozos, y el resto de instalaciones superficiales ligadas a ellos, junto con las escombreras, los elementos patrimoniales que permitirán, en un ejercicio creativo, dibujar en superficie el yacimiento mineral profundo, dando información sobre el legado geológico bajo la superficie: disposición, orientación y dimensión aproximada de los filones, así como su contenido mineral y tipo de roca encajante.

Sin embargo, no en todos los espacios mineros la puesta en valor de este patrimonio geológico es posible. La morfología del yacimiento bajo el subsuelo, la existencia o no de pozos identificables en superficie o la conservación de las escombreras in situ, juegan un papel fundamental en el proceso de reconstrucción del patrimonio subyacente.

En este sentido, el caso de La Carolina se muestra extraordinariamente favorable al contar con todos los elementos imprescindibles para tal fin. En primer lugar, la mineralización adquiere bajo la superficie una geometría con tendencia tabular y, por tanto, fácilmente reproducible en superficie; los filones que albergan la mineralización son estructuras lineales, generalmente de extensión considerable y con una dirección determinada. En segundo lugar, la existencia de pozos mineros, tanto maestros como auxiliares, bien conservados en superficie y conectados directamente con los filones permiten determinar la orientación y longitud aproximada de los mismos; para ello es imprescindible la existencia de al menos dos pozos alineados, mejorando notablemente el trazado de los filones cuanto mayor número de pozos se conserven. Por último, la presencia de escombreras, en su mayoría no removilizadas, en las que se acopia en el exterior el material procedente de la explotación subterránea y que permiten suministrar, de forma directa, muestras de la mineralización y de la roca encajante.

De este modo, la recuperación del patrimonio geológico oculto es posible, y con ello, una interpretación completa, global y visual del espacio minero a partir de los elementos que lo conforman.

Este trabajo aporta la información y la metodología necesaria para llevar a cabo, desde el punto de vista del patrimonio geológico invisible, la musealización del espacio que discurre por las minas del Castillo, La Rosa, El Sinapismo y La Aquisgrana, basada en el diseño de paneles en los que se recrearán los filones del subsuelo vinculados con los elementos patrimoniales superficiales, mejorando indudablemente la imagen, hasta ahora incompleta, de este singular espacio. El encaje de todos los elementos patrimoniales geológicos y mineros, visibles e invisibles, permite dimensionar el espacio minero más allá de los sistemas constructivos observados en superficie. Ello evidencia, igualmente, la organización jerárquica que se establece entre estos elementos patrimoniales: la existencia de unos y su ubicación (elementos geológicos del subsuelo) condiciona directamente la presencia y distribución de los otros (restos mineros de la superficie).

\section{AgRADECIMIENTOS}

Esta aportación se inscribe dentro de la actividad “Apoyo al Parque Temático Geológico-Minero en el sector de la Aquisgrana, La Carolina (Jaén)" en el marco del Convenio específico de colaboración entre la Excma. Diputación de Jaén y el Instituto Geológico y Minero de España para el período 2017-2019.

\section{BiBLIOGRAFíA}

Arboledas, L. (2007). Minería y metalurgia romana en el Alto Guadalquivir: aproximación desde las fuentes escritas y el registro arqueológico, Tesis Doctoral, Universidad de Granada, Granada.

Arboledas, L., Contreras, F. y Moreno, A. (2014). La explotación minera antigua en Sierra Morena oriental y su vinculación con el territorio. Cuadernos de Prehistoria y Arqueología de la Universidad de Granada, 24, 111-145.

Azcárate, J. E. (1971). Estudio metalogenético comparativo de las mineralizaciones plumbíferas de Linares-La Carolina-Sta. Elena. Informe no 10395, SID-IGME.

Azcárate, J.E. (1977). Mapa geológico y memoria explicativa de la hoja 905 (Linares), escala 1:50.000. Plan Magna del Instituto Geológico y Minero de España.

Azcárate, J. E. y Argüelles, A. (1971). Evolución tectónica y estructuras filonianas en el distrito de Linares. Congreso Hispano-Luso-Americano de Geología Económica, Madrid. Tomo 1, Sección 4 (pp. 17-32).

Boixereu, E., Palero, F., Marimón, J. y Feixas, C. (2011). Descripción de las mineralizaciones de la Zona Centroibérica. En Cartografía de recursos minerales de Andalucía (A. García Cortés, Ed. Ppal.), IGME-Consejería de Economía, Innovación y Ciencia de la Junta de Anadlucía. Madrid (pp. 61-79)

Cañizares, M. C. (2011). Patrimonio, parques mineros y turismo en España. Cuadernos de Turismo, 27, 133-153. 
Carrera, G., Delgado, A. y Zafra, P. (2006). Ruta cultural en el antiguo distrito de Linares-La Carolina. PH Boletín del Instituto Andaluz del Patrimonio Histórico, 61, 92-103.

Castelló, R. y Orviz, F. (1976). Mapa geológico y memoria explicativa de la hoja 884 (La Carolina), escala 1:50.000. Plan Magna del Instituto Geológico y Minero de España.

Colectivo Proyecto Arrayanes (2010). La puesta en valor del patrimonio minero del distrito Linares-La Carolina. Una propuesta integral, en Contreras y Dueñas (Ed.). La minería y la metalurgia en el Alto Guadalquivir: desde sus orígenes hasta nuestros días (pp. 373-384). Instituto de Estudios Giennenses, Jaén, España.

Contreras, F. y Dueñas, J. (2010). La minería y la metalurgia en el Alto Guadalquivir: desde sus orígenes hasta nuestros días, Instituto de Estudios Giennenses y Diputación Provincial de Jaén, Jaén,

De la Torre, M. J., Campos, M. J. e Hidalgo, M.C. (2010). Estudio mineralógico de las escombreras en el distrito minero de La Carolina (Jaén, España). Revista de la Sociedad Española de Mineralogía, 13, 213-214.

Díaz-Martínez, E. (2017). Marco conceptual para la gestión y conservación del patrimonio minero. En: O.Puche, M. Ayarzagüena, J.F. López y J. Pous (Eds). Minería y Metalurgia Históricas en el Sudoeste Europeo. SEDPGyM, Madrid, 411-416.

Dueñas, J., Hidalgo, M.C. y Rey, J. (2000). Itinerario minero en el distrito de La Carolina (Jaén). En: Rábano, I. (Ed.), Patrimonio geológico y minero en el marco del Desarrollo Sostenible. Colección Temas Geológico-Mineros, 31, 457-464.

Domergue, C. (2000). En busca del plomo de las minas romanas del distrito Linares-La Carolina (Jaén). En Rábano, I. (Ed.). Patrimonio Geológico y Minero en el marco del desarrollo sostenible. Colección Temas Geológico-Mineros, 31, 61-67.

Eiffel Lab (2020). Minas de Sierra Morena. Recuperado de http://www.minasdesierramorena.es/guia-decampo/conjuntos-mineros/linares-la-carolina/

Fernández, R. (1954). Reseña histórica de la minería del plomo en la zona de Linares-La carolina. Actas conmemorativas de la creación del Cuerpo de Ingenieros de Minas. Madrid.

García, A., Rosique, M. F. y Torres, M. (2017). Topografía y cartografía minera. Cartagena, España: Universidad Politécnica de Cartagena.
Galdón, J. M. (2018). Análisis de la viabilidad técnica para la puesta en valor turístico del patrimonio minero-industrial en el paraje de la Aquisgrana en La Carolina (Jaén). Universidad de Jaén, Jaén.

Galdón, J. M., Rey, J., Martínez, J. y Martínez, S. (2016). Propuesta de reutilización sostenible del espacio minero de la Aquisgrana en La Carolina (Jaén) como parque temático con fines turísticos y culturales. Actas del IX Congreso Internacional obre Minería y Metalurgia. Sociedad Española para la Defensa del Patrimonio Geológico y Minero (pp. 435-443). España.

Galdón, J. M., Rey, J., Martínez, J. y Martínez, S. (2017). Análisis de viabilidad técnica para la puesta en valor turístico del patrimonio minero-industrial en el paraje de la Aquisgrana en la Carolina (Jaén). Actas del XI Congreso Internacional de Historia de la Minería IMHC20165 (pp. 285-291). Universidad de Jaén, España.

García-Cortés, A. (Ed. Ppal.)(2011). Cartografía de recursos minerales de Andalucía. IGME-Consejería de Economía, Innovación y Ciencia de la Junta de Andalucía. Madrid, España.

Gutiérrez, F. (2007). Minería en Sierra Morena II. EI distrito minero de la Carolina. Editado por el Ilustre Colegio Oficial de Ingenieros Técnicos de Minas de Linares, Granada, Jaén y Málaga.

Gutiérrez, L. M. (2010). Minería antigua en Sierra Morena, Universidad de Jaén, Jaén.

Hernández, A. M. (2004). El parque minero de Almadén. En Incua, Asociación de Arqueología Industrial (Ed.). Rutas culturales y turísticas del patrimonio industrial (pp. 177-180). España.

IGME (1973). Mapa Metalogenético de España, Hoja 70 (Linares), Escala 1:200.000. Instituto Geológico y Minero de España.

Lillo, F. J. (1992). Geology and Geochemistry of Linares-La Carolina Pb-ores field (Southeastern border of the Hesperian Massif). Thesis Univ. Leeds.

López-Morell,M. A. (2003). Peñarroya: un modelo de corporación minero-industrial, 1881-1936. Revista de Historia Industrial, 23, 95-13.

Martín, A. y Puche, O., (2000). Recuperación de minas e instalaciones mineras antiguas. En Rábano, I. (Ed.). Patrimonio Geológico y Minero en el marco del desarrollo sostenible. Colección Temas Geológico-Mineros, 491-507. 
Martín, L.M., González-Lodeiro, F., Martín-Poyatos, D. J. y Matas, J. (2019). Mapa geológico y memoria explicativa de la hoja 862 (Santa Elena), escala 1:50.000. Plan Magna del Instituto Geológico y Minero de España.

Martín, L. M., Matas, J., Roldán, F. J. y Martín-Serrano, A. (1982). Mapa geológico y memoria explicativa de la hoja 70 (Linares), escala 1:200.000.

Martos, J. (1880). Guía de Linares y su provincia Jaén. Linares, Colegio Oficial de Ingenieros Técnicos de Minas de Linares.

Ministerio de Industria (1971). Plan Nacional de la Minería. Programa Nacional de Explotación Minera: minería del plomo y zinc. Depósito Legal: M.28007/1971.

Muñoz, J., Alonso, J.A. y Martín, J. (2002). Involución y autarquía: la economía española entre 1890 y 1914 . Madrid, España, Editorial Complutense.

Pérez de Perceval, M. A. y López-Morell, M. A. (2008). Inversión extranjera en la minería murciana. IX Congreso AEHE. Sesión: Economía Política de la Inversión Extranjera en España y desde España, S. XIX y XX. Recuperado de https://webs.um.es/ perceval/wp-content/uploads/2012/06/2008Inversion-ext-IX-AEHE.pdf

Pérez de Perceval, M. A. y Sánchez, A. (2010). Patrimonio minero: un variopinto y problemático mundo de vestigios. Áreas. Revista Internacional de Ciencias Sociales, 29,51-59.

Rey, J. e Hidalgo, M.C. (2004). Siliciclastic sedimentation and sequence stratigraphic evolution on a storm-dominated shelf: the lower Ordovician of the Central Iberian Zone (NE Jaén, Spain). Sedimentary Geology, 164, 89-104.

Rey, J., Hidalgo, M.C. y Martínez-López, J. (2005). Upper Ordovician-Lower Silurian trangressiveregressive cycles of the Central Iberian Zone (NE Jaén, Spain). Geological Journal, 20, 1-19.

Roll, M. (2012). Fuentes documentales en el Archivo Histórico Provincial de Jaén para el estudio de la Sociedad Minera "El Centenillo". Revista Andaluza de Archivos, 5, 89-112.

Tamain, G. (1972). Recherches géologiques et minières en Sierra Morena orientale (Espagne). Thèse présentée à l'université de Paris-sud (Centre d'Orsay). Trav. Lab. Géol. Struct. Appli. 91-Orsay; T: I, II.

Tamain, G. (1974). L'information archeologique appliquee a la prospection miniere et a la geologie en Sierra Morena Orientale (Espagne). Inst. Sci. Terre, Univ. Orsay. http://info.igme.es/ConsultaSID/ presentacion.asp? $\mathrm{Id}=10803$

\section{NOTAS}

1. BDMIN, Base de datos de Recursos Minerales del Instituto Geológico y Minero de España, http://doc.igme.es/bdmin/ (Fecha de consulta, 15/02/2020).

2. BOJA, Boletín Oficial de la Junta de Andalucía https://www.juntadeandalucia.es/boja/2008/90/ index.html

3. Estadística Minera de España, http://info.igme. es/estminera/informes/1909.pdf\#page=214

4. Estadística Minera de España, http://info.igme. es/estminera/informes/1911.pdf\#page=289 